\title{
Regulating loot boxes as gambling? Towards a combined legal and self-regulatory consumer protection approach
}

\author{
Leon Y. Xiao*
}

\begin{abstract}
Loot boxes represent a popular and prevalent contemporary monetization innovation in video games that offers the purchasing player-consumer, who always pays a set amount of money for each attempt, the opportunity to obtain randomized virtual rewards of uncertain in-game and real-world value. Loot boxes have been, and continue to be, scrutinized by regulators and policymakers because their randomized nature is akin to gambling. The regulation of loot boxes is a current and challenging international public policy and consumer protection issue. This article reviews the psychology literature on the potential harms of loot boxes and applies the behavioural economics literature in order to identify the potentially abusive nature and harmful effects of loot boxes, which justify their regulation. This article calls on the industry to publish loot box spending data and cooperate with independent empirical research to avoid overregulation. By examining existing regulation, this article identifies the flaws of the 'regulate-loot-boxes-as-gambling' approach and critiques the alternative consumer protection approach of adopting ethical game design, such as disclosing the probabilities of obtaining randomized rewards and setting maximum spending limits. This article recommends a combined legal and self-regulatory approach: the law should set out a minimum acceptable standard of consumer protection and industry self-regulation should strive to achieve an even higher standard.
\end{abstract}

Keywords: loot boxes, video game law, video gaming regulation, consumer protection, gambling, video games, microtransactions, ethical game design

\section{Introduction}

'Loot boxes' are consumable virtual items in video games that can be redeemed (or 'opened') by players to receive randomized rewards, which may be merely cosmetic, or which may influence the game more significantly by unlocking additional game content or manipulating the player's in-game power. This article adopts a wide interpretation of the meaning of 'loot boxes' to include other randomized monetization methods in video games which may not necessarily be represented as a 'box': for example, treasure chests; military supply crates; card packs; gacha prize dispensers; and prize wheels. In some games, these rewards may be transferable between players and accordingly gain real-world monetary value. ${ }^{1}$ Randomized game mechanics in general are arguably inherent to game design and have been implemented in video games for decades. ${ }^{2}$ However, paid loot boxes specifically, i.e., loot boxes that require the payment of real-world money to obtain (rather than loot boxes that are obtained 'for free' by completing ingame tasks, such as defeating enemies ${ }^{3}$ ) is a relatively recent monetization innovation that has been the subject
* leon.xiao.y@gmail.com; The Honourable Society of Lincoln's Inn, Lin coln's Inn, London WC2A 3TL, UK; Durham Law School, Durham University, Palatine Centre, Stockton Rd, Durham DH1 3LE, UK; Josephine Butler College, Durham University, South Rd, Durham DH1 3DF, UK; The City Law School, City, University of London, Northampton Square, Clerkenwell, London EC1V 0HB, UK.

1 Aaron Drummond and others, 'Why Loot Boxes Could Be Regulated as Gambling' (2020) 4 Nature Human Behaviour 986; David Zendle and others, 'Paying for Loot Boxes Is Linked to Problem Gambling, Regardless of Specific Features Like Cash-out and Pay-to-Win' (2019) 102 Computers in Human Behavior 181; Leon Y. Xiao, 'Which Implementations of Loot Boxes Constitute Gambling? A UK Legal Perspective on the Potential
Harms of Random Reward Mechanisms' (2020) Advance Online Publication. International Journal of Mental Health and Addiction, available at: https://doi.org/10.1007/s11469-020-00372-3 (accessed 10 June 2021).

2 Rune Kristian Lundedal Nielsen and Pawel Grabarczyk, 'Are Loot Boxes Gambling? Random Reward Mechanisms in Video Games' (2019) 4 Transactions of the Digital Games Research Association 171, 175-179.

3 Non-paid loot boxes have been hypothesized to also be potentially harmful by normalizing gambling behaviour, especially in relation to children, see Xiao (fn 1). However, the empirical basis for this assertion remains to be established; therefore, this article focuses on paid loot boxes. 
of public controversy ${ }^{4}$ and regulatory scrutiny ${ }^{5}$ due to its randomized nature and apparent similarity to gambling.

The origin of the loot box mechanic can be traced back to the collectible and tradable sports cards of the mid-20th century. ${ }^{6}$ Loot boxes were inspired by the successful monetization of Magic: The Gathering (1993, Wizards of the Coast), a tabletop trading card game, ${ }^{7}$ which, instead of selling a complete collection of every available card to its players, sells blind sealed packages of randomized cards of varying power and value that forces players to effectively purchase duplicate cards, and thereby spend more money than they otherwise would have to, in order to obtain a complete collection. ${ }^{8}$ Magic: The Gathering has relied upon and sustained itself on this same lucrative business model through to the present day. The initial digital implementations of loot boxes were in free-to-play games on mobile phones that relied solely on paid loot boxes to monetize, e.g., Puzzle \& Dragons (2012, GungHo Online Entertainment). Such games adopt the 'freemium' business model: instead of directly selling all of their content outright, they offer a portion of their content to players for free as an alternative business strategy in order to attract the largest possible userbase, and then monetized by convincing a portion of that userbase they have attracted to make optional 'premium' in-game purchases and unlock more content. ${ }^{9}$ However, loot boxes are now also commonly implemented in full-priced games on consoles and PCs, e.g., Overwatch (2015, Blizzard Entertainment). ${ }^{10}$ Such games originally monetized based solely on title sales, but now also implement loot boxes as an additional, supplementary monetization method.

The adoption of alternative monetization methods, such as implementing loot boxes, is a highly successful attempt by the video game industry to respond to commercial pressures within the rapidly developing but hypercompetitive industry, ${ }^{11}$ such as meeting consumer pressures to keep title prices low despite increasing production costs; rampant piracy facilitated by illegal online file-sharing, including torrenting, that digital rights management (DRM) has failed to prevent technologically; and the pressing need for less-established game companies to explore alternative business models and user acquisition methods, such as freemium, in an over-saturated market. ${ }^{12}$ The prevalent implementation of loot boxes reflects a change in the business model of many video games to rely significantly on 'microtransactions': this transition can be conceptualized as 'game as a service', which will be provided and paid for segmentally and periodically over a length of time (e.g., subscriptionbased monthly 'battle pass' systems), as compared to the traditional 'game as a product' conceptualization by which a game was provided and sold at once as a complete package. This change brings positive effects to consumers, such as increased accessibility to gaming products (including free access to entertainment content that may otherwise be unaffordable), and the freedom to choose to pay for video gaming services in manners more suitable to the player's own financial situation and desired amount of dedication to a particular game. Nonetheless, the widespread implementation of paid loot boxes in video games is concerning because the player can now spend a potentially unlimited amount of money on individual video games, which may lead to overspending.

Loot boxes are currently prevalent in video games; are purchased by a significant percentage of players; and are deemed suitable for purchase by children. Macey and Hamari concluded that loot boxes are presently 'prevalent in all types and genres of contemporary video games $^{13}$ and that their purchase is widely popular with esports participants across all age groups (46\% of those surveyed purchased loot boxes). ${ }^{14}$ Zendle et al.'s survey of the UK games market found that $56 \%$ of highest-grossing mobile games on iOS and Android, and $36 \%$ of highest-grossing desktop games on Steam,
4 Mainly in response the implementation of loot boxes in Star Wars Battlefront 2 (2017, Electronic Arts), see GameSpot Staff, 'Star Wars Battlefront 2's Loot Box Controversy Explained' (GameSpot, 22 November 2017), available at: https://www.gamespot.com/articles/star-wars-battlefront-2sloot-box-controversy-expl/1100-6455155/ (accessed 10 June 2021); Nielsen and Grabarczyk (fn 2) 172.

5 Xiao (fn 1).

6 Nielsen and Grabarczyk (fn 2) 176. See also Sara A. Elliott and Daniel S. Mason, 'Emerging Legal Issues in the Sports Industry: Are Trading Cards a Form of Gambling?' (2003) 13 Journal of Legal Aspects of Sport 101, 103.

7 See Jan Švelch, 'Mediatization of a Card Game: Magic: The Gathering, Esports, and Streaming' (2020) 42 Media, Culture \& Society 838, 842.

8 Greg Costikyan, Uncertainty in Games (MIT Press, 2013) 67-68; Nielsen and Grabarczyk (fn 2) 176. of Magic: The Gathering's now-expired patent detailed how the duplicate cards were intended to encourage trading between players, see Richard Channing Garfield, 'Patent No.
US5662332A: Trading Card Game Method of Play' (United States Patent and Trademark Office, 1994) 11.

9 Some free-to-play games' content can potentially be accessed entirely for free if the player is willing to invest significant amounts of their time.

10 Nielsen and Grabarczyk (fn 2) 178.

11 Sebastian Schwiddessen and Philipp Karius, 'Watch Your Loot Boxes! Recent Developments and Legal Assessment in Selected Key Jurisdictions From a Gambling Law Perspective' (2018) 1 Interactive Entertainment Law Review 17, 19.

12 Andrew Moshirnia, 'Precious and Worthless: A Comparative Perspective on Loot Boxes and Gambling' (2018) 20 Minnesota Journal of Law, Science \& Technology 77, 84-85.

13 Joseph Macey and Juho Hamari, 'eSports, Skins and Loot Boxes: Participants, Practices and Problematic Behaviour Associated with Emergent Forms of Gambling' (2019) 21 New Media \& Society 20, 28.

14 Ibid 32, 35. 
contained loot boxes, and that $93 \%$ of Android games containing loot boxes were deemed suitable for children aged $12+$ and $57 \%$ were also deemed suitable for children aged $7+{ }^{15}$ The UK Gambling Commission's 2019 survey found that $28 \%$ of $11-16$-year-olds in the UK have used in-game items and $23 \%$ have paid money to open loot boxes. ${ }^{16} 62 \%$ of Australian games examined by Rockloff et al. contained loot boxes. ${ }^{17}$ Loot boxes may be even more prevalent in non-Western countries: Xiao et al.'s survey of the 100 highest-grossing iPhone games in the People's Republic of China (PRC) found that $91 \%$ contained loot boxes, and that $90.5 \%$ of the games deemed suitable for children aged $12+$ contained loot boxes. ${ }^{18}$

Conclusive data on loot box spending (either total or per individual player) cannot be collated because such data are held by game companies and they do not release loot box sales data to the public. Juniper Research predicted that total spending on loot boxes and 'skins gambling' (i.e., gambling on, inter alia, eSports tournament results using in-game cosmetic items, including those obtained from loot boxes ${ }^{19}$ ) will rise from under US $\$ 30$ billion (approximately $£ 21.6$ billion) in 2018 to US $\$ 50$ billion (approximately $£ 35.9$ billion) in $2022 .{ }^{20}$ Approximately $20 \%$ of all surveyed Heroes of the Storm (2015, Blizzard Entertainment) players were classified as problem gamblers on the Problem Gambling Severity Index: ${ }^{21}$ such players were documented to have individually spent on average US\$83.86 (approximately $\mathfrak{E 6 0 \text { ) }}$ monthly on the loot boxes of just this one game. ${ }^{22}$ Players may well be invested in and playing multiple games simultaneously, and therefore spending money buying loot boxes in multiple games. Therefore, actual average monthly individual spending on loot boxes may be many times more than Zendle's findings. Indeed, mainstream media has reported extreme cases, demonstrating public attention to the issue: four children spent 'nearly $£ 550$ in three weeks' on loot boxes using their father's bank account without permission and still failed to get the rare item they were after. ${ }^{23}$ Another player discovered that he has 'spent over US\$10,000 [(approximately $\mathfrak{E 7 , 1 8 9 ) ]}$ in just two years' on the loot boxes of one single game by requesting his personal data from the game company using data protection legislation ${ }^{24}$ this latter case also demonstrates that game companies have indeed collected and are in possession of data on individual player's loot box spending.

The statistics cited demonstrate that the video game industry has a significant financial interest in loot boxes and may be incentivized to ensure their continued un-regulation, and that the regulation of loot boxes is a substantial issue that impacts many people across the world, including vulnerable groups, such as children. Accordingly, the regulation of loot boxes may be justifiable to prevent potential gambling-related harms and, regardless of any contravention of gambling laws, to ensure consumer protection in general.

\section{Potential gambling-related harms}

Loot boxes are structurally similar to gambling because they possess elements in common with gambling and satisfy Griffiths' definition of gambling in psychology. ${ }^{25}$ The purchase of loot boxes has been identified as an 'emergent gambling behaviour'. ${ }^{26}$ The randomized nature of loot boxes is arguably designed to encourage purchase
15 David Zendle and others, 'The Prevalence of Loot Boxes in Mobile and Desktop Games' (2020) 115 Addiction 1768, 1770.

16 UK Gambling Commission, 'Young People and Gambling Survey 2019: A Research Study among 11-16 Year Olds in Great Britain' (2019) 39, available at: https://www.gamblingcommission.gov.uk/PDF/Young-PeopleGambling-Report-2019.pdf (accessed 10 June 2021).

17 Matthew Rockloff and others, 'Loot Boxes: Are They Grooming Youth for Gambling?' (Central Queensland University 2020) 32, available at: https:// doi.org/10.25946/5ef151aclce6f (accessed 10 June 2021).

18 Leon Y. Xiao and others, 'Gaming the System: Sub-Optimal Compliance with Loot Box Probability Disclosure Regulations in China' (2021) Behavioural Public Policy (forthcoming), available at: https://psyarxiv.com/ e6yw8/ (accessed 10 June 2021).

19 Skins gambling is another gambling-related video game issue that should be addressed either by law or self-regulation to ensure consumer protection, especially in relation to vulnerable groups, such as children. The psychology literature on loot boxes, and how loot boxes will be addressed by the industry and by regulators, may inform the regulation of skins gambling. However, skins gambling is not within the ambit of this article.

20 Juniper Research, 'In-Game Gambling - the Next Cash Cow for Publishers' (2018) 4, available at: https://www.juniperresearch.com/documentlibrary/white-papers/in-game-gambling-the-next-cash-cow (accessed 10 June 2021).
21 David Zendle, 'Problem Gamblers Spend Less Money When Loot Boxes Are Removed from a Game: A before and after Study of Heroes of the Storm' (2019) 7 PeerJ e7700, 7.

22 Ibid 11.

23 Zoe Kleinman, 'The Kids Emptied Our Bank Account Playing Fifa' (BBC News, 9 July 2019), available at: https://www.bbc.co.uk/news/technology48908766 (accessed 10 June 2021).

24 Wesley Yin-Poole, 'FIFA Player Uses GDPR to Find out Everything EA Has on Him, Realises He's Spent over $\$ 10,000$ in Two Years on Ultimate Team' (Eurogamer, 25 July 2018), available at: https://www.eurogamer. net/articles/2018-07-23-fifa-player-uses-gdpr-to-find-out-everything-eahas-on-him-realises-hes-spent-over-usd10-000-in-two-years-on-ultimateteam (accessed 10 June 2021).

25 Aaron Drummond and James D. Sauer, 'Video Game Loot Boxes Are Psychologically Akin to Gambling' (2018) 2 Nature Human Behaviour 530. See Mark D. Griffiths, Adolescent Gambling (Routledge, 1995) 1-2. A wider interpretation of 'gambling' may conclude that an even higher proportion of loot boxes are structurally similar to gambling, see Leon Y Xiao, 'Conceptualising the Loot Box Transaction as a Gamble Between the Purchasing Player and the Video Game Company' (2020) Advance online publication. International Journal of Mental Health and Addiction, available at: https://doi.org/10.1007/s11469-020-00328-7 (accessed 10 June 2021)

26 Macey and Hamari (fn 13) 20. 
in manners similar to gambling. ${ }^{27}$ Certain implementations of loot boxes may be 'predatory' because they 'disguise or withhold the true long-term cost of the activity until players are already financially and psychologically committed'. ${ }^{28}$ Zendle and Cairns' large-scale survey, based on the players' self-reported quantitative measures of the intensity of their problem gambling on the Problem Gambling Severity Index, demonstrated 'an important relationship between problem gambling and the use of loot boxes', ${ }^{29}$ which is that: ' $\mathrm{t}$ ] $\mathrm{he}$ more severe that participants' problem gambling was, the more money they spent on loot boxes'. ${ }^{30}$ Subsequent psychology research has generally consistently reported some relationship between problem gambling and loot boxes. ${ }^{31}$ It ought to be noted that the positive correlation between loot box spending and problem gambling severity does not prove causation in either direction: ${ }^{32}$ it is not known whether existing problem gamblers spend more on loot boxes; whether loot boxes cause people to become problem gamblers; or whether there are other confounding variables. Further research is required to conclusively identify the exact nature of the relationship between loot boxes and gambling (if any); however, arguably, further independent research is currently being stifled by the video game industry's general failure to be socially responsible by cooperating with academics by providing verifiable player spending data on loot boxes.

Players' potentially problematic escalating desire to purchase and open loot boxes may be explained by applying the behavioural psychology concept of 'reinforcement'. ${ }^{33}$ Skinner demonstrated that a certain desired behaviour can be 'reinforced' in a subject through a gradual process of incrementally 'rewarding' behaviours which constitute correct steps towards the formation of that certain desired final behaviour. ${ }^{34}$ Rare and valuable prizes obtained from loot boxes have been likened in popular media to 'rewards' which are able to 'positively reinforce' the player behaviour of purchasing and opening more loot boxes through the release, in the player's brain, of dopamine, ${ }^{35}$ a neurotransmitter activated by rewards, and which causes 'wanting' and potentially 'addiction'. ${ }^{36}$ The randomized and unpredictable value of the rewards obtained from loot boxes qualifies their reward schedule as the variable-ratio schedule of reinforcement. $^{37}$ This particular schedule of reinforcement rewards the subject unpredictably such that they are forced to exhibit the desired behaviour repeatedly, even when they are not guaranteed to obtain a reward for each instance of doing so, in the hope that any one such instance of the desired behaviour would finally
27 Digital, Culture, Media and Sport Committee of the House of Commons (UK), 'Immersive and Addictive Technologies: Fifteenth Report of Session 2017-19’ (2019) HC 1846, paras 121, 123, available at: https://publications. parliament.uk/pa/cm201719/cmselect/cmcumeds/1846/1846.pdf (accessed 10 June 2021).

28 Daniel L. King and Paul H. Delfabbro, 'Predatory Monetization Schemes in Video Games (e.g. "Loot Boxes”) and Internet Gaming Disorder' (2018) 113 Addiction 1967, 1967.

29 David Zendle and Paul Cairns, 'Video Game Loot Boxes Are Linked to Problem Gambling: Results of a Large-Scale Survey' (2018) 13 PLOS ONE e0206767, 6 .

30 Ibid 6-7.

31 See David Zendle and Paul Cairns, 'Loot Boxes Are Again Linked to Problem Gambling: Results of a Replication Study' (2019) 14 PLOS ONE e0213194; Zendle and others (fn 1); Gabriel A. Brooks and Luke Clark, 'Associations between Loot Box Use, Problematic Gaming and Gambling, and Gambling-Related Cognitions' (2019) 96 Addictive Behaviors 26; Søren Kristiansen and Majbritt Christine Severin, 'Loot Box Engagement and Problem Gambling among Adolescent Gamers: Findings from a National Survey' (2019) 103 Addictive Behaviors 106254; Wen Li, Devin Mills and Lia Nower, 'The Relationship of Loot Box Purchases to Problem Video Gaming and Problem Gambling' (2019) 97 Addictive Behaviors 27; Chanel J. Larche and others, 'Rare Loot Box Rewards Trigger Larger Arousal and Reward Responses, and Greater Urge to Open More Loot Boxes' (2021) 37 Journal of Gambling Studies 141; Andrew Brady and Garry Prentice, 'Are Loot Boxes Addictive? Analyzing Participant's Physiological Arousal While Opening a Loot Box' (2021) 16 Games and Culture 419; Heather Wardle and David Zendle, 'Loot Boxes, Gambling, and Problem Gambling Among Young People: Results from a Cross-Sectional Online Survey' (2021) 24 Cyberpsychology, Behavior, and Social Networking 267; Aaron Drummond and others, 'The Relationship between Problem Gambling, Excessive Gaming, Psychological Distress and Spending on Loot Boxes in Aotearoa New Zealand, Australia, and the United States A Cross-National Survey' (2020) 15 PLOS ONE e0230378; Lauren C.
Hall and others, 'Effects of Self-Isolation and Quarantine on Loot Box Spending and Excessive Gaming-Results of a Natural Experiment' (2021) 9 PeerJ e10705.

32 Zendle and Cairns (fn 31) 11.

33 Rockloff and others (fn 17) 21.

34 B.F. Skinner, Science and Human Behavior (first published 1953, B.F. Skinner Foundation, 2014) 92, available at: http://www.bfskinner.org/new testsite/wp-content/uploads/2014/02/ScienceHumanBehavior.pdf (accessed 10 June 2021).

35 See Nathan Lawrence, 'The Science Behind Why We Love Loot' (Game Informer, 23 October 2015), available at: https://www.gameinformer.com/b/ features/archive/2015/10/23/the-science-behind-why-we-love-loot.aspx (accessed 10 June 2021); Alex Wiltshire, 'Behind the Addictive Psychology and Seductive Art of Loot Boxes' (PC Gamer, 28 September 2017), available at: https://www.pcgamer.com/behind-the-addictive-psychology-and-seduc tive-art-of-loot-boxes/ (accessed 10 June 2021); Heather Alexandra, 'Loot Boxes Are Designed to Exploit Us' (Kotaku, 13 October 2017), available at: https://kotaku.com/loot-boxes-are-designed-to-exploit-us-1819457592 (accessed 10 June 2021).

36 For the current understanding of the role of dopamine in the context of reward and addiction in psychology, in relation to incentive salience, see Kent C. Berridge and Terry E. Robinson, 'What Is the Role of Dopamine in Reward: Hedonic Impact, Reward Learning, or Incentive Salience?' (1998) 28 Brain Research Reviews 309; Kent C. Berridge, 'The Debate Over Dopamine's Role in Reward: The Case for Incentive Salience' (2007) 191 Psychopharmacology 391; Kent C. Berridge, Terry E. Robinson and J. Wayne Aldridge, 'Dissecting Components of Reward: "Liking", "Wanting”, and Learning' (2009) 9 Neurosciences 65.

37 Vic Hood, 'Are Loot Boxes Gambling?' (Eurogamer, 12 October 2017), available at: https://www.eurogamer.net/articles/2017-10-11-are-lootboxes-gambling (accessed 10 June 2021); Drummond and Sauer (fn 25) 530, 531; Moshirnia (fn 12) 87. 
elicit a reward. ${ }^{38}$ This schedule of reinforcement is widely known to and heavily abused by gambling operators. ${ }^{39}$ The psychology literature appreciates that the positive reinforcement framework, particularly the variable-ratio schedule of reinforcement, is capable of causing the acquisition of extremely persistent behaviours, e.g., gambling and, perhaps by extension, purchasing and opening loot boxes, and therefore can explain why loot boxes may constitute a predatory monetization method. ${ }^{40}$

\subsection{Loot boxes may abuse irrational biases}

In addition to loot boxes' link with problem gambling and their potential abuse of the variable-ratio schedule of reinforcement, loot boxes may also be predatory because they present and abuse experimentally demonstrable decisionmaking cognitive biases and fallacies of the player, ${ }^{41}$ and thereby cause players to make irrational, 'maladaptive purchasing decisions' ${ }^{42}$ It is arguable that, when influenced and misled by decision-making biases, the player's 'choice' to purchase and open loot boxes is no longer free, voluntary and informed. This is synonymous with how gamblers are influenced by fallacies and decision-making heuristics, ${ }^{43}$ which simplify judgement but may lead to 'severe and systematic errors' ${ }^{44}$ For example, ignoring any house rules, the popular game of 38-pocket American roulette has an expected value of $-5.26 \%$, thus a bet of $\$ 1$ is expected to, in the long-term, on average, lose $\$ 0.0526 .{ }^{45}$ Playing roulette in these circumstances is irrational. Nonetheless, gamblers continue willingly to make the decision of betting on roulette and participating in other gambling games, and losing their money because they are influenced by decision-making fallacies which cause them to make irrational decisions. ${ }^{46}$

38 C.B. Ferster and B.F. Skinner, Schedules of Reinforcement (first published 1957, B.F. Skinner Foundation, 2015) ch 7, available at: http://www.bfskinner. org/wp-content/uploads/2015/05/Schedules_of_Reinforcement_PDF.pdf (accessed 10 June 2021)

39 Skinner (fn 34) 104; See also Terry J. Knapp, 'Behaviorism and Public Policy: B.F. Skinner's Views on Gambling' (1997) 7 Behavior and Social Issues 129.

40 See e.g. Drummond and Sauer (fn 25) 530; Zendle (fn 21) 2.

41 Daniel L. King and Paul H. Delfabbro, 'Loot Box Limit-Setting Is Not Sufficient on Its Own to Prevent Players from Overspending: A Reply to Drummond, Sauer \& Hall' (2019) 114 Addiction 1324, 1324; Nielsen and Grabarczyk (fn 2) 183-185.

42 King and Delfabbro (fn 28) 1967.

43 See Richard A. Epstein, The Theory of Gambling and Statistical Logic (Academic Press, 1967) ch 11.

44 Amos Tversky and Daniel Kahneman, 'Judgment under Uncertainty: Heuristics and Biases' (1974) 185 Science 1124, 1124.

45 Epstein (fn 43) 131-135.

46 See D.B. Cornish, Gambling, a Review of the Literature and Its Implications for Policy and Research: A Home Office Research Unit Report (Home Office Research Study 42, Her Majesty's Stationery Office, 1978) ch 11.
Irrational biases, previously identified to arise in relation to gambling, may also be abused by game companies to cause players to purchase more loot boxes than they otherwise would have. One such bias has been identified as 'entrapment', whereby 'a decision-maker continues to expend resources at least in part to justify previous, hitherto unfulfilled, expenditures ${ }^{3}{ }^{47}$ For example, 'when the gambler wishes to recoup losses he has already incurred and therefore decides to roll the dice "just one more time". ${ }^{48}$ Similarly, the loot box-purchasing player may wish to justify the losses they have incurred in their previous failed loot box openings (when they did not obtain the rewards they wanted) by buying even more loot boxes in the hope of finally obtaining their desired valuable rewards; therefore, entrapment may deceptively cause the player to make 'maladaptive' loot box purchasing decisions. ${ }^{49}$

Another such bias is the 'gambler's fallacy'. ${ }^{50}$ For example, '[a]fter observing a long run of red on the roulette wheel, most people erroneously believe that black is now due .... ${ }^{51}$ Such gamblers are failing to rationally recognize independent random events as independent, ${ }^{52}$ and are instead irrationally and erroneously interrelating them. ${ }^{53}$ The gambler's fallacy could apply to the purchasing and opening of loot boxes because players may erroneously interrelate each independent loot box openings and believe that they would gain a better chance of 'winning' and opening valuable content after successively 'losing' and failing to obtain rare items. Accordingly, the gambler's fallacy is capable of misleading the player into purchasing more loot boxes immediately after they had just failed to obtain rare items from a prior batch of loot box purchases, which would result in the player spending more money on loot boxes than they had previously intended to or budgeted for. It is

47 Joel Brockner, Myril C. Shaw and Jeffrey Z. Rubin, 'Factors Affecting Withdrawal from an Escalating Conflict: Quitting Before It's Too Late' (1979) 15 Journal of Experimental Social Psychology 492, 493.

48 Jeffrey Z. Rubin and Joel Brockner, 'Factors Affecting Entrapment in Waiting Situations: The Rosencrantz and Guildenstern Effect' (1975) 31 Journal of Personality and Social Psychology 1054, 1054.

49 King and Delfabbro (fn 28) 1967; Daniel L. King and others, 'Unfair Play? Video Games as Exploitative Monetized Services: An Examination of Game Patents from a Consumer Protection Perspective' (2019) 101 Computers in Human Behavior 131, 140-141.

50 See Daniel Kahneman and Amos Tversky, 'Belief in the Law of Small Numbers' (1971) 76 Psychological Bulletin 105, 106; Gideon B. Keren and Willem A. Wagenaar, 'On the Psychology of Playing Blackjack: Normative and Descriptive Considerations With Implications for Decision Theory' (1985) 114 Journal of Experimental Psychology: General 133, 149-150.

51 Tversky and Kahneman (fn 44) 1125.

52 Charles T. Clotfelter and Philip J. Cook, 'Notes: The "Gambler's Fallacy" in Lottery Play' (1993) 39 Management Science 1521, 1521.

53 Paul Rogers, 'The Cognitive Psychology of Lottery Gambling: A Theoretical Review' (1998) 14 Journal of Gambling Studies 111, 119. 
particularly concerning that some games manipulate the probabilities of obtaining rarer rewards according to the player's spending behaviour: 'pity-timer' mechanics increase the probabilities of acquiring rarer rewards, or guarantee their acquisition, after the player has failed to obtain the rarer rewards in prior attempts. ${ }^{54}$ These pity-timers arguably reinforce the gambler's fallacy by literally making it true with regards to certain, but not all, loot boxes: players may erroneously assume that all loot boxes have an in-built pity-timer mechanic.

Pity-timers must record the player's purchasing behaviour (e.g., what rewards they received on previous occasions) and use this data in order to automatically determine when to increase probabilities. A review of patents granted to video game companies revealed that the industry has at least considered, if not already implemented, using players' behavioural tracking data that they have collected and analysed (e.g., what types of items a particular player likes to purchase; how much remaining in-game balance they have; and what items they already possess) to automatically adjust aspects of the in-game product offerings (e.g., pricing and availability of certain types of items). ${ }^{55}$ The player's data are being used by the video game companies to maximize commercial gain, which arguably means that the player's data are being processed in a way that is not in their best interest, and may potentially be 'exploitative'. ${ }^{56}$ Video game companies may be required by data protection legislation to obtain consent from the player before using their data in such manners. However, it remains arguable whether the data collected would be 'personal data'. The use of children's data for such purposes without consent (e.g., providing 'birthday offers' by misusing children's personal data collected for age verification purposes ${ }^{57}$ ) would not be in the children's best interests and may be a contravention of data protection legislation and codes of practice, such as the UK Information Commissioner's Office's Age Appropriate Design Code. ${ }^{58}$

The third irrational bias that loot boxes may abuse is the 'near-miss effect'. ${ }^{59} \mathrm{~A}$ 'near-miss' occurs when 'an unsuccessful outcome is proximal to the designated win, such as when a chosen horse finishes in second place or when two cherries are displayed on the slot machine payline' ${ }^{60}$ The near-miss effect refers to how the presentation of a losing situation as a near-miss encourages players to make further attempts. ${ }^{61}$ Clark et al. argued that 'the recruitment of win-related regions [of the brain] during near-miss outcomes underlies their ability to promote gambling behavior. ${ }^{62}$ Loot box openings are often presented with explosive visual animation and celebratory audio effects regardless of the value of the rewards obtained. Arguably, loot boxes are designed to build anticipation in the player similar to gambling, ${ }^{63}$ and to disappoint that player in order to expose them to a near-miss so as to encourage further purchases.

Reid suggested that people inexperienced with gambling may be more prone to the near-miss effect. ${ }^{64}$ This is particularly worrying and relevant to the potential regulation of loot boxes because many players engaging with loot boxes do not necessarily realize that they are gambling when they play video games. Indeed, 16 regional gambling regulators ${ }^{65}$ have expressed their concerns with the risks posed by 'the blurring of lines between gambling and ... video gaming'. ${ }^{66}$ Loot boxes are randomized, not 'innocent' and may represent 'games of
54 Leon Y. Xiao and Laura L. Henderson, 'Towards an Ethical Game Design Solution to Loot Boxes: A Commentary on King and Delfabbro' (2019) Advance online publication. International Journal of Mental Health and Addiction 7, available at: https://doi.org/10.1007/s11469-019-00164-4 (accessed 10 June 2021); see also King and others (fn 49); Xiao and others (fn 18); Nick Ballou, Charles Takashi Toyin Gbadamosi and David Zendle, 'The Hidden Intricacy of Loot Box Design: A Granular Description of Random Monetized Reward Features' 10, available at: https://doi.org/ 10.31234/osf.io/xeckb (accessed 10 June 2021).

55 King and others (fn 49) 139.

56 Ibid

57 Information Commissioner's Office (ICO), 'Age Appropriate Design: A Code of Practice for Online Services' (2020) 35, available at: https://ico.org.uk/ media/for-organisations/guide-to-data-protection/key-data-protectionthemes/age-appropriate-design-a-code-of-practice-for-online-services-2-1. pdf (accessed 10 June 2021)

58 Ibid 88 .

59 Autorité de regulation des jeux en ligne (ARJEL) [Regulatory Authority for Online Games] (France), 'Rapport d'activité 2017-2018 [Activity Report 2017-2018]' (2018) 5, available at: https://web.archive.org/web/ 20200414184944/http://www.arjel.fr/IMG/pdf/rapport-activite-2017.pdf (accessed 10 June 2021); Cecilia D’Anastasio, 'Why Opening Loot Boxes Feels Like Christmas, According To Game Devs' (Kotaku, 20 March 2017), available at: https://kotaku.com/why-opening-loot-boxes-feels- like-christmas-according-1793446800 (accessed 10 June 2021); Moshirnia (fn 12) 87; David Zendle, Rachel Meyer and Harriet Over, 'Adolescents and Loot Boxes: Links With Problem Gambling and Motivations for Purchase' (2019) 6 Royal Society Open Science: 190049, 4; Zendle and others (fn 1) 183.

60 Luke Clark and others, 'Gambling Near-Misses Enhance Motivation to Gamble and Recruit Win-Related Brain Circuitry’ (2009) 61 Neuron 481, 481.

61 R.L. Reid, 'The Psychology of the Near Miss' (1986) 2 Journal of Gambling Behavior 32, 32.

62 Clark and others (fn 60) 485

63 See Larche and others (fn 31); Brady and Prentice (fn 31).

64 Reid (fn 61) 36.

65 Fifteen of the regulators are from Europe and represent: Austria, Czechia (the Czech Republic), France, Gibraltar, Ireland, the Isle of Man, Jersey, Latvia, Malta, The Netherlands, Norway, Poland, Portugal, Spain, the United Kingdom; and one, the Washington State Gambling Commission, is from the United States of America.

66 UK Gambling Commission and others, 'Declaration of Gambling Regulators on Their Concerns Related to the Blurring of Lines Between Gambling and Gaming' (2018), available at: https://www.gamblingcommission.gov.uk/ $\mathrm{PDF} /$ International-gaming-and-gambling-declaration-2018.pdf (accessed 10 June 2021) 
chance', but they are presented (or, if viewed more cynically, hidden) within video games which are generally perceived as 'games of skill'. ${ }^{67}$ The conflation of these two activities, referred to as the gaming-gambling convergence, ${ }^{68}$ is socially worrying and a 'clear public concern' because consumers may be unable to differentiate between the video game itself and (quasi-)gambling elements incorporated into it (e.g., loot boxes), such that, for example, children may end up gambling unknowingly with 'money intended for computer game products' given to them to spend by their similarly unknowing parents. ${ }^{69}$

\subsection{Call for game companies to release loot box spending data}

Actual loot box purchasing data collected and possessed by game companies ${ }^{70}$ are required to conduct comprehensive, empirical investigations on the relationship between loot boxes and gambling; to confirm if the additional introduction of any irrational biases outlined above induces maladaptive loot box purchases; and to assess the potential harms of loot boxes in general. However, currently, such crucial data have not been made available by game companies for independent research. Although this failure to release data can be appreciated from a commercial standpoint, this position does not treat consumers fairly, and is socially irresponsible and arguably unethical. Although such data may be commercially sensitive as they may reveal the amount of total sales and active user numbers, game companies should proactively collaborate with researchers to find appropriate ways to desensitize and anonymize the data released. ${ }^{71}$ For example, the limited release of the anonymized spending data of 1000 random users would reveal a very limited amount of business sensitive information, but would still assist empirical research significantly. The release of such data may also give rise to

67 See Belgische Kansspelcommissie [Belgian Gaming Commission], 'Belgian Gaming Commission Rules after Analysis: "Paying Loot Boxes Are Games of Chance"', available at: https://www.gamingcommission.be/opencms/ opencms/jhksweb_en/gamingcommission/news/news_0061.html (accessed 10 June 2021).

68 Heather Wardle, 'The Same or Different? Convergence of Skin Gambling and Other Gambling Among Children' (2019) 35 Journal of Gambling Studies 1109.

69 UK Gambling Commission, 'International Concern Over Blurred Lines Between Gambling and Video Games' (17 September 2018), available at: http://www.gamblingcommission.gov.uk/news-action-and-statistics/ News/international-concern-over-blurred-lines-between-gambling-andvideo-games (accessed 10 June 2021).

70 As compared to experimental loot box purchasing data that may be collected by researchers using a specially designed which would not have been derived from a commercially viable video game, or potentially biased and inaccurate anecdotal data reported by players themselves. data protection concerns; however, an update to the privacy policy and appropriate anonymization of data should resolve any such issues. Most players would likely welcome such research even knowing that their data would be used.

The applicability and effectiveness of industry data to research were demonstrated by Zendle who took advantage of the removal of paid loot boxes from Heroes of the Storm in March $2019^{72}$ and conducted a survey which demonstrated that 'When loot boxes were removed from Heroes of the Storm, problem gamblers spent significantly less money in-game'. ${ }^{73}$ However, Zendle's conclusion was only tentative due to a lack of verifiable datasets: Zendle was only able to rely on unverifiable, self-reported data from players. Only with the release of industry data by game companies for further independent empirical research could the many questions surrounding the potential harms of loot boxes be fully assessed and answered. ${ }^{74}$ Currently, there is an 'information asymmetry' between elements of the video game industry that implement paid loot boxes and the public: these companies are in possession of data (if not also the results) as to the potential harms of loot boxes, but the public and regulators are forced by these companies to have access to little, if any, information. This information asymmetry renders the current relationship between these companies and the public arguably inequitable, and renders the current relationship between these companies and regulators 'evasive' and disingenuous. ${ }^{75}$

\subsection{The industry is divided on the ethics of implementing loot boxes}

It ought to be recognized that different video game companies hold divergent perspectives on the continued implementation of loot boxes and the ethical implications of doing so, in light of potential harms to players. When giving evidence to the Digital, Culture, Media and

71 Whilst also ensuring that no conflicts of interests arise, e.g., when a certain company's game is incidentally 'promoted' by empirical research for being less harmful, especially when other companies were not given the opportunity to be assessed in a comparable manner.

72 No reasoning was provided for this removal, see Blizzard Entertainment, 'Heroes of the Storm PTR Patch Notes - March 18, 2019' (Heroes of the Storm Official Website, 18 March 2019), available at: https://news.blizzard com/en-us/heroes-of-the-storm/22933130/heroes-of-the-storm-ptr-patchnotes-march-18-2019 (accessed 10 June 2021).

73 Zendle (fn 21) 11

74 Ibid.

75 See Clive Efford, Matthew Weissinger and Canon Pence, Oral Evidence (Questions 1156-1157) to the Immersive and Addictive Technologies Inquiry of the Digital, Culture, Media and Sport Committee of the House of Commons (UK) (2019), available at: http://data.parliament. $\mathrm{uk} /$ writtenevidence/committeeevidence.svc/evidencedocument/digitalculture-media-and-sport-committee/immersive-and-addictive-technolo gies/oral/103191.pdf (accessed 10 June 2021). 
Sport Committee of the UK House of Commons (DCMS Committee), Kerry Hopkins, Vice President for Legal at Electronics Arts, refused to recognize paid loot boxes implemented in FIFA Ultimate Team as paid 'loot boxes' and characterized them as 'quite ethical and quite fun'. ${ }^{76}$ In contrast, Epic Games has changed the design of paid loot boxes in Fortnite by implementing 'X-Ray Llamas', whose rewards are revealed to the player prior to purchase: the player will know exactly what they will receive before they spend money and thus are allowed to make a more informed purchasing decision. ${ }^{77}$ These X-Ray Llamas' content is still randomized automatically on a daily basis before being shown to the player, so if the player does not like the randomized content on a particular day, they can wait a number of days for the content to be eventually changed to rewards they do like before purchasing. This effectively removed randomization from the X-Ray Llamas' purchasing process, but not from the mechanic itself. This arguably ensures that they are still 'quite fun' as the content that the player can choose to purchase (or not) is still randomized on a daily basis and may be a nice, unexpected surprise for the player to look forward to, but also more 'ethical' because the change avoids requiring players to blindly pay for randomized content that they do not want. This change effectively rendered the product no longer a 'loot box' per se and more akin to purchasable additional game content, i.e., 'DLCs', because the player knows exactly what they are buying. In contrast, Blizzard Entertainment appears indecisive on the issue as it has removed paid loot boxes from Heroes of the Storm, ${ }^{78}$ but continues to sell them in Hearthstone (2014, Blizzard Entertainment). Other game companies never implemented loot boxes in their games in the first place and have no plans to do so in the future: Metronomik, an indie developer, has recognized the ethical issues relating to the implementation of paid loot boxes and refused to

76 Kerry Hopkins, Oral Evidence (Question 1142) to the Immersive and Addictive Technologies Inquiry of the Digital, Culture, Media and Sport Committee of the House of Commons (UK) (2019), available at: http:// data.parliament.uk/writtenevidence/committeeevidence.svc/evidencedo cument/digital-culture-media-and-sport-committee/immersive-andaddictive-technologies/oral/103191.pdf (accessed 10 June 2021).

77 Fortnite Team, 'Loot Unboxing' (Fortnite Official Website, 25 January 2019), available at: https://www.epicgames.com/fortnite/en-US/news/ loot-unboxing (accessed 10 June 2021). See also Rebekah Valentine, 'Epic Games Commits to Loot Box Transparency across Portfolio' (GamesIndustry.biz, 9 August 2019), available at: https://www.gamesindustry.biz/ articles/2019-08-09-epic-games-commits-to-loot-box-transparencyacross-portfolio (accessed 10 June 2021).

78 Zendle (fn 21). See fn 72.

79 Ellia Pikri, 'A Glimpse into Wan Hazmer's New RM300K M'sian Project After The Success Of FFXV' (Vulcan Post, 22 May 2018), available at: https:/vulcanpost.com/640032/wan-hazmer-metronomik-malaysia-game/ (accessed 10 June 2021). implement them despite potential commercial loss. ${ }^{79}$ Given the current notoriety of and aversion to paid loot boxes amongst video game players, it is arguable whether the decision not to implement loot boxes by a particular game company could be seen as an 'ethical' decision that is capable of being appreciated by players and may be promoted by the media, ${ }^{80}$ and would in turn drive up sales of the game and be a better commercial decision in the long-term than implementing paid loot boxes.

Although the industry does not hold a uniform position on whether paid loot boxes are ethical, ${ }^{81}$ the industry's failure to release data for independent research has been universal. For companies that are continuing to implement paid loot boxes in video games, their failure to cooperate with regulators and researchers by providing loot box spending data is socially irresponsible and arguably unethical, but may be excused for commercial reasons, given that the area remains unregulated in most countries. However, companies that have already stopped implementing paid loot boxes (perhaps in recognition of the ethical implications), but are still in possession of players' past loot box spending data from when the companies did sell loot boxes, would not necessarily be negatively affected by the prospective regulation of loot boxes and may be in a better position to release these data for independent research. In fact, the release of this data may benefit socially responsible companies immediately through positive publicity, and also long-term if prospective regulation of loot boxes would divert spending on loot boxes to other more ethical video gaming monetization methods. However, no such release has been forthcoming. Socially responsible game companies that are in a position to gain (or at least in a position not to lose) from the release of loot box spending data should publish it and support independent research. ${ }^{82}$
80 See text to fn 188 .

81 And whether particular implementations of paid loot boxes are ethical, e.g., the 'pay-to-win' business model, whereby a player can only be competitive when compared to other players if they continually invest money into the game by purchasing newly released products, see Schwiddessen and Karius (fn 11) 19.

82 For academics, policymakers and NGO representatives calling for the release of industry data, see, inter alia, Zendle (fn 21) 10; Letter from Margaret Wood Hassan to Patricia Vance (14 February 2018) 2, available at: https://www.hassan.senate.gov/imo/media/doc/180214.ESRB.Letter.Final. pdf (accessed 10 June 2021); Federal Trade Commission (US), 'Inside the Game: Unlocking the Consumer Issues Surrounding Loot Boxes, Session 2' (Public Workshop, Washington, DC, US, 7 August 2019), available at: https://www.ftc.gov/news-events/audio-video/video/inside-gameunlocking-consumer-issues-surrounding-loot-boxes-session-2 (accessed 10 June 2021) video record timestamps 1:52:54-1:53:08 


\subsection{Pre-emptive regulation justified by the precautionary principle?}

The DCMS Committee, in its recent inquiry report, argued that the 'precautionary principle' (that 'the lack of scientific certainty cannot justify [regulatory] inactivity in cases of high risk ${ }^{83}$ ) should apply to justify the pre-emptive regulation of loot boxes, because game companies cannot prove that the monetization schemes which they have designed and implemented, such as loot boxes, are not harmful. ${ }^{84}$ The Committee went above and beyond only calling for game companies to release industry data for research into the extent of the potential harm of loot boxes in order to better inform potential regulation: the Committee argued that it is no longer necessary for academics or regulators to prove that loot boxes represent a predatory monetization method and are harmful in order to justify regulation, and that it is now instead the responsibility of the game companies implementing these monetization methods to prove that loot boxes are not predatory and harmful in order to justify the continued lack of regulation. The DCMS Committee's assertion is worrying in that negative proof of loot boxes not being harmful is impossible to obtain from a scientific perspective: it is literally asking the industry to provide the impossible. ${ }^{85} \mathrm{~A}$ more reasonable approach would be to ask for evidence that harm is unlikely or minimal.

The DCMS Committee recommended that UK gambling law should be amended in due course after consultation to regulate paid loot boxes, ${ }^{86}$ whilst, only a few months later, the Gambling Industry Committee of the UK House of Lords recommended the immediate regulation of paid loot boxes as gambling by executive regulations without waiting for further consultation. ${ }^{87}$ These recommendations teeter on the edge of overregulation and mirror the position taken by the Belgian gambling regulator (that all paid loot boxes constitute gambling regardless of whether their rewards are worth real-world money, and that consumers' access to all loot boxes would be

83 Miguel Á Recuerda Girela, 'Risk and Reason in the European Union Law' (2006) 1 European Food and Feed Law Review 270, 285.

84 Digital, Culture, Media and Sport Committee of the House of Commons (UK) (fn 27) para 79.

85 Xiao, 'Which Implementations of Loot Boxes Constitute Gambling?' (fn 1).

86 Digital, Culture, Media and Sport Committee of the House of Commons (UK) (fn 27) paras 97-98.

87 Select Committee on the Social and Economic Impact of the Gambling Industry of the House of Lords (UK), 'Report of Session 2019-21: Gambling Harm - Time for Action' (2020) HL Paper 79, para 446, available at: https:// web.archive.org/web/20200702195336/https://publications.parliament.uk/ pa/ld5801/ldselect/ldgamb/79/79.pdf (accessed 10 June 2021).

88 Belgische Kansspelcommissie [Belgian Gaming Commission], 'Onderzoeksrapport loot boxen [Research Report on Loot Boxes]' (2018) 17, available at: https://www.gamingcommission.be/opencms/export/sites/ prohibited, unless they are appropriately licensed as regulated gambling ${ }^{88}$ ), which has led to the complete removal of certain games from the Belgian market because operating them in that country was no longer commercially viable, e.g., Animal Crossing: Pocket Camp (2017, Nintendo \& NDcube) ${ }^{89}$ and therefore deprived consumers of the opportunity to play certain games. An overly paternalistic outright ban of loot boxes also unduly restricts the industry's creative output and economic potential ${ }^{90}$ (although forcing game companies to stop defaulting to monetizing with loot boxes and instead invent and experiment with other more ethical monetization methods may revitalize creativity). Both game companies and players lose out when loot boxes are overregulated. These comparatively drastic regulatory positions that have been recommended (a version of which has been adopted in Belgium ${ }^{91}$ ) suggest that, if the video game industry continues to be uncooperative when working with independent researchers and regulators, overregulation negatively affecting the industry creatively and commercially may be the inevitable result. The industry should be welladvised to act responsibly now to avoid this undesirable yet potentially imminent outcome of overregulation.

In the Author's opinion, certain implementations of loot boxes are defensible. The most prominent problem with paid loot boxes is potential overspending. ${ }^{92} \mathrm{~A}$ loot box implementation released monthly whose rewards are all guaranteed to be obtained if the maximum capped spending of $\mathfrak{E 3 0}$ is reached by the player is defensible because the player cannot overspend. Similarly, a paid loot box mechanic that can simultaneously be relatively easily accessed by performing non-paid in-game actions, such as logging-in to the game or defeating enemies, would also make the implementation more defensible. Indeed, if the rewards of the loot box do not influence the player's in-game powers (and perhaps only make cosmetic changes), and would not advantage the player when compared to other players or a hypothetical version of themself who did not purchase loot boxes, then

default/jhksweb_nl/documents/onderzoeksrapport-loot-boxen-final-pub licatie.pdf (accessed 10 June 2021).

89 Nintendo, 'Belangrijke informatie voor gebruikers in België [Important Information for Users in Belgium]' (Nintendo Belgium, 21 May 2019), available at: https://www.nintendo.be/nl/Nieuws/2019/mei/Belangrijkeinformatie-voor-gebruikers-in-Belgie-1561911.html (accessed 10 June 2021)

90 Xiao and Henderson (fn 54) 10. See also Moshirnia (fn 12) 111-112.

91 Belgische Kansspelcommissie [Belgian Gaming Commission] (fn 88) 17.

92 Notwithstanding the potential harms of non-paid loot boxes and other seemingly harmless gambling references 'normalizing' gambling behaviours by making them appear to be regular social activities that 'normal' people engage with, as such potential harms remain to be empirically established, see Xiao, 'Which Implementations of Loot Boxes Constitute Gambling?' (fn 1). 
this implementation also becomes more defensible. These changes in loot box implementation which try to prevent overspending and avoid placing undue pressures on the consumer to spend money (such as when a loot box is made available for purchase only for a limited time) can be referred to as 'ethical game design'. ${ }^{93}$ Therefore, in the Author's opinion, the consumer protection issue relating to loot boxes needs not necessarily be solved by the outright ban of loot boxes, which may negatively affect game companies financially and deny players access to certain video game content, and which may not be the best solution to the problem for all parties involved. Accordingly, the prohibitive gambling law approach to regulating loot boxes should be critiqued.

\section{Regulating loot boxes as gambling? A divergent approach with limited national success}

The obvious regulatory response to loot boxes has been to examine whether they constitute 'gambling' under existing gambling regulation, and to classify and regulate them as such if they do. The benefit of directly adopting existing gambling law to potentially regulate loot boxes is that such laws are already legislated and in effect, and therefore can be immediately executively applied by relevant regulators, if appropriate.

To oversimplify the divergent gambling laws of various jurisdictions, 'gambling' is generally conceived of in law as requiring three elements: 'stake'; 'chance'; and 'prize'. 94 Certain implementations of loot boxes may plainly constitute gambling under existing laws by satisfying these elements. However, each jurisdiction defines each element differently, and may add or remove elements: for example, under UK law, the 'prize' must be worth real-world

93 For other ethical game design measures that game companies should consider implementing, see Daniel L. King and Paul H. Delfabbro, 'Video Game Monetization (e.g., "Loot Boxes"): A Blueprint for Practical Social Responsibility Measures' (2019) 17 International Journal of Mental Health and Addiction 166. See also Xiao and Henderson (fn 54).

94 Annette Cerulli-Harms and others, 'Loot Boxes in Online Games and Their Effect on Consumers, in Particular Young Consumers' (Policy Department for Economic, Scientific and Quality of Life Policies (EU) 2020) PE 652.727 34-35, available at: https://www.europarl.europa.eu/ RegData/etudes/STUD/2020/652727/IPOL_STU(2020)652727_EN.pdf (accessed 10 June 2021). See also Daniel L. King, 'Online Gaming and Gambling in Children and Adolescents - Normalising Gambling in Cyber Places: A Review of the Literature' (Victorian Responsible Gambling Foundation 2018) 21-22, available at: https://web.archive.org/web/ 20200629185932/https://responsiblegambling.vic.gov.au/documents/479/ Online-gaming-and-gambling-in-children-and-adolescents_.pdf (accessed 10 June 2021).

95 See UK Gambling Commission, 'Virtual Currencies, ESports and Social Gaming - Position Paper' (2017) 7, para 3.17, available at: http://www. gamblingcommission.gov.uk/PDF/Virtual-currencies-eSports-and-socialcasino-gaming.pdf (accessed 10 June 2021). money for the element to be satisfied; ${ }^{95}$ in contrast, in Belgium, there is no 'prize' element per se, and Belgian gambling law instead examines whether there is a 'chance of wins or losses' ${ }^{96}$ A prize that is not worth real-world money is nonetheless a 'win' under Belgian gambling law. ${ }^{97}$ Different gambling laws mean that certain implementations of loot boxes may constitute gambling in one jurisdiction, but not in another. ${ }^{98}$ For example, the UK Gambling Commission opined that only loot boxes which are both paid for and which provide rewards worth real-world money constitute 'gambling', 99 and that neither non-paid loot boxes (which may nonetheless provide rewards worth real-world money), nor paid loot boxes that do not provide rewards worth real-world money constitute 'gambling' ${ }^{100}$ The Dutch ${ }^{101}$ and French ${ }^{102}$ gambling regulators came to similar conclusions. In contrast, the Belgian gambling regulator opined that paid loot boxes constitute gambling regardless of whether their rewards can be transferred between players and therefore possess real-world value. ${ }^{103}$ Indeed, contrary to popular belief, Belgian gambling law was never amended to extend to loot boxes: pre-existing Belgian gambling law was already capable of being interpreted to include loot boxes because of its drafting language. ${ }^{104}$

In addition to a jurisdictional divergence as to the legal definitions of gambling, a divergence as to enforcement can also be identified even between the Dutch, and the UK and French regulators: although they have taken similar regulatory positions on which implementations of loot boxes constitute gambling, they enforce their positions to different degrees. The Dutch regulator was much less sympathetic towards game companies, who ostensibly explicitly disallow the transfer and selling of ingame items between players (which would give them real-world value) but nonetheless implicitly facilitate such activities. ${ }^{105}$ The Dutch regulator opined that 97 98 99

01 Kansspelautoriteit [The Netherlands Gambling Authority], 'Onderzoek naar loot boxes: Een buit of een last? [Study into Loot Boxes: A Treasure or a Burden?]' (2018) para 4, available at: https://web.archive.org/web/ 20200628120004/https://www.kansspelautoriteit.nl/publish/library/6/ onderzoek_naar_loot_boxes_-_een_buit_of_een_last_-_nl.pdf (accessed 10 June 2021).

102 Autorité de regulation des jeux en ligne (ARJEL) [Regulatory Authority for Online Games] (France) (fn 59) 5, 7.

103 Belgische Kansspelcommissie [Belgian Gaming Commission] (fn 88) 17. 104 Ibid.

105 See Cerulli-Harms and others (fn 94) 36. However, note that CerulliHarms et al. are incorrect in stating that loot boxes of the E-I [(Embedded-Isolated)] type are therefore also considered gambling under the Dutch legislation'. E-I type loot boxes are not considered gambling under Dutch gambling law. The implementations of loot boxes 
such implementations constitute gambling, and has fined Electronic Arts for implementing such loot boxes in its FIFA games (after Electronic Arts failed to change its loot box implementation despite being notified that it was in violation of Dutch gambling law) to enforce compliance with Dutch gambling law and to 'shield vulnerable groups, such as minors, from exposure to gambling' ${ }^{106}$ This fine was approved by the District Court of The Hague. ${ }^{107}$ Electronic Arts is presently appealing this decision on the ground that it believes the Dutch gambling regulator's and the court's interpretation of Dutch gambling law is erroneous. ${ }^{108}$ In contrast, the UK and French regulators gave game companies the benefit of the doubt and determined that such transfer facilities do not necessarily render a loot box 'gambling' if and when the game companies have attempted to restrict the players' ability to transfer and sell in-game items. The UK regulator opined that the restriction has to be 'successful', ${ }^{109}$ in the sense that game companies must not inadvertently allow such transfer facilities, but no prosecution or other enforcement action has been brought in the UK against evidently 'unsuccessful' implementations that can be and have been so exploited. ${ }^{110}$ The French regulator decided that, at present, the potential monetization of the prizes through third-party websites has not been explicitly authorized by the game operator, and, therefore, the prizes of such loot boxes do not possess monetary value.111

\subsection{The need for a universal, international standard of loot box regulation}

Cerulli-Harms et al. have argued that the European Single Market is being 'fragmented' and negatively impacted by various European national gambling regulators taking divergent regulatory approaches to loot boxes because certain games can no longer be marketed in countries like Belgium and the Netherlands. ${ }^{12}$ This would likely lead to increased compliance costs, as different versions

identified by the Dutch regulator as offending Dutch gambling law have been E-E (Embedded-Embedded) type loot boxes whose rewards can be transferred to other players and sold for real-world money, although most are ostensibly, but falsely, presented by video game companies as E-I type loot boxes (e.g., Electronic Arts' FIFA games discussed at text to fns 106-108). On this point, see Xiao, 'Which Implementations of Loot Boxes Constitute Gambling?' (fn 1) 13-14.

106 Kansspelautoriteit [The Netherlands Gambling Authority], 'Imposition of an Order Subject to a Penalty on Electronic Arts for FIFA Video Game' (29 October 2020), available at: https://web.archive.org/web/ 20201127222346/https://kansspelautoriteit.nl/nieuws/nieuwsberichten/ 2020/oktober/imposition-an-order/ (accessed 10 June 2021).

107 Electronic Arts Inc \& Electronic Arts Swiss Sàrl v Kansspelautoriteit (2020) Rechtbank Den Haag [District Court of The Hague] (15 October 2020), available at: https://uitspraken.rechtspraak.nl/inziendocument?id=ECLI: NL:RBDHA:2020:10428 (accessed 10 June 2021).

108 Brendan Sinclair, 'EA Fined $€ 10 \mathrm{~m}$ over Loot Boxes as Dutch Court Sides with Gambling Authority' (GamesIndustry.biz, 29 October 2020), available of the same video game may need to be produced to comply with the laws of various countries. CerulliHarms et al. suggested that a common European Union regulatory approach would be able to ensure consumer protection across the Single Market. ${ }^{113}$

The potential harms of paid loot boxes do not appear to be related to whether their prizes are worth real-world money; paid loot boxes whose rewards are not transferable and are not worth real-world money appear to be just as potentially harmful. ${ }^{114}$ When a certain implementation of loot boxes constitutes gambling in a certain jurisdiction, then it should be regulated as gambling in that jurisdiction. Unfortunately, not all implementations of paid loot boxes fall under the definitions of gambling in all jurisdictions. This means that consumers are protected only if they happen to live in a country whose existing gambling law covers both paid loot box types. Presently, a universal, international standard of consumer protection in relation to loot boxes is lacking. Indeed, currently, only Belgian consumers are fully protected, as all paid loot boxes have been removed. In the Netherlands, game companies complied by only removing paid loot box reward transfer features (thus ensuring that loot box rewards are not worth real-world money), without removing paid loot boxes themselves. ${ }^{115}$ Dutch consumers remain exposed to the potential harms of paid loot boxes whose rewards are not worth real-world money. The contrast in compliance by $2 \mathrm{~K}$ Games in the Netherlands and Belgium is particularly telling of the difference in national regulatory positions. ${ }^{116}$ Players in other countries, such as the UK, are exposed to even more potential harms because of non-enforcement of the law. Consumer protection is not ensured universally as it should be.

All paid loot boxes should be regulated regardless of whether their rewards are worth real-world money, but not necessarily as gambling per se. Multiple papers in the legal literature and gambling regulators have attempted to fit the regulation of loot boxes into the

at: https://www.gamesindustry.biz/articles/2020-10-29-ea-fined-10mover-loot-boxes-as-dutch-court-sides-with-gambling-authority (accessed 10 June 2021)

109 See UK Gambling Commission, 'Position Paper' (fn 95) para 3.18.

110 See Drummond and others (fn 1); Xiao, 'Which Implementations of Loot Boxes Constitute Gambling?' (fn 1).

111 Autorité de regulation des jeux en ligne (ARJEL) [Regulatory Authority for Online Games] (France) (fn 59) 7

112 Cerulli-Harms and others (fn 94) 42.

113 Ibid 42-43.

114 Zendle and others (fn 1) 188, 190.

115 2K Games, 'Statement Netherlands' (2018), available at: https://www.2k. com/myteaminfo/nl/ (accessed 10 June 2021); cf $2 \mathrm{~K}$ Games, 'Statement Belgium' (2018), available at: https://www.2k.com/myteaminfo/be/ (accessed 10 June 2021).

116 See ibid. 
existing gambling law framework of various jurisdictions $^{117}$ (e.g., arguing that certain implementations should constitute illegal lottery gambling under Californian law $\left.^{118}\right)$. Such assessments often fail in relation to paid loot boxes whose rewards are not worth realworld money because the 'prize' element cannot be satisfied. However, in the Author's opinion, the inability of existing gambling law in many jurisdictions to include paid loot boxes whose rewards are not worth realworld money should be accepted. Hasty amendments to gambling law that extends existing definitions of gambling to cover such implementations of loot boxes, as for example recommended by the DCMS Committee in the $\mathrm{UK},{ }^{119}$ are not necessarily well-advised: expanding the legal concept of what may constitute 'prizes,' specifically the meaning of 'money's worth' in the UK to include perceived non-monetary value, ostensibly only for the purpose of regulating loot boxes, may potentially unfairly render other harmless activities, and other activities which are unlikely to be harmful, 'gambling' in the eyes of the law and unduly restrict people's ability to engage with them. Additionally, regulating loot boxes as gambling would face the same difficulties encountered by the regulation of online gambling in general, including complications with enforcement when consumers gamble with overseas service providers. ${ }^{120}$

The regulate-loot-boxes-as-gambling approach was an expedient first step to quickly address potential loot boxes harms. However, the regulation of loot boxes should also be approached from a more holistic consumer protection perspective, in addition to applying existing gambling law, in order to provide more comprehensive consumer protection. ${ }^{121}$ Ethical game design measures that seek to minimize harms include, amongst others: disclosing the probabilities of obtaining potential rewards; establishing maximum spending limits; and disabling 'cashout' features. ${ }^{122}$ These three measures have been partially implemented in certain countries and as self-regulation by the industry in other jurisdictions. The practicality of regulating through and enforcing these measures is critiqued, and recommendations as to how to improve their implementation in the future are made.

\section{Consumer protection measures}

\subsection{Disclosure of the probabilities of obtaining potential rewards}

The PRC did not approach the regulation of loot boxes from a gambling perspective: instead, video gaming service providers in the PRC are required to disclose the probabilities of obtaining potential rewards. ${ }^{123}$ The video game industry has also generally been accepting of this measure as a self-regulation solution in other jurisdictions. ${ }^{124}$ For example, the Entertainment Software Association (ESA) announced that the video game industry is 'committing' to 'further inform[ing] consumer purchases': the three leading hardware providers, Sony; Microsoft and Nintendo, 'will require paid loot boxes in games developed for their platforms to disclose information on the relative rarity or probability of obtaining randomized virtual items'. ${ }^{125}$ The ESA's proposal would have a global reach and will likely better protect many consumers across the world. The ESA also identified that several major game publishers already disclose such information in their games. ${ }^{126}$ Apple and Google both also require probability disclosures for games published on their respective app stores which contain paid loot boxes. ${ }^{127}$
117 See e.g., Moshirnia (fn 12) 97-107; Schwiddessen and Karius (fn 11) 23-42; David J. Castillo, 'Unpacking the Loot Box: How Gaming's Latest Monetization System Flirts with Traditional Gambling Methods' (2019) 59 Santa Clara Law Review 165, 176-193; Edwin Hong, 'Loot Boxes: Gambling for the Next Generation' (2019) 46 Western State Law Review 61, 68-78; Kevin Liu, 'A Global Analysis into Loot Boxes: Is It “Virtually” Gambling?' (2019) 28 Washington International Law Journal 763, 778-788.

118 Hong (fn 117) 65-68

119 Digital, Culture, Media and Sport Committee of the House of Commons (UK) (fn 27) paras 97-98

120 See Adrian Parke and Mark Griffiths, 'Why Internet Gambling Prohibition Will Ultimately Fail' (2004) 8 Gaming Law Review 295, 296-298.

121 See Cerulli-Harms and others (fn 94) 42-43.

122 For other ethical game design measures, see text to fns 93, 179-182.

123 文化部 [Ministry of Culture] (PRC), “文化部关于规范网络游戏运营加 强事中事后监管工作的通知 [Notice of the Ministry of Culture on Regulating the Operation of Online Games and Strengthening Concurrent and Ex-Post Supervisions] 文市发〔2016〕32号”(1 December 2016) para 6, available at: https://web.archive.org/web/20171220060527/http:// www.mcprc.gov.cn:80/whzx/bnsjdt/whscs/201612/t20161205_464422. html (accessed 10 June 2021).
124 In Japan and South Korea, respectively, see NHN Japan 株式会社 [NHN Japan Corporation] and others, ‘ゲーム内表示等に関するガイドライ ン [Guidelines for In-Game Disclosures and Other Matters]' (2012) 1-3, arts 3-5, available at: https://web.archive.org/web/20120709220824/http:/ www.gree.co.jp/news/press/2012/0622_01/In-game_display_guidelines.pdf (accessed 10 June 2021); 한국게임산업협회 [Korea Association of Game Industry; K-GAMES], '건강한 게임문화 조성을 위한 자율규제 시행 기준 [Criteria on Implementation of Self-Regulation for Healthy Game Culture]' (2018) 2, art 5, available at: http://www.gsok.or.kr/regulationson-self-regulation $/$ ?uid $=89 \& \bmod =$ document\&pageid $=1$ (accessed 10 June 2021).

125 Entertainment Software Association (ESA), 'Video Game Industry Commitments to Further Inform Consumer Purchases' (7 August 2019), available at: https://www.theesa.com/perspectives/video-game-industry-commitmentsto-further-inform-consumer-purchases/ (accessed 10 June 2021).

126 Ibid.

127 Apple, 'App Store Review Guidelines' (Apple Developer, 11 September 2020), available at: https://developer.apple.com/app-store/review/guidelines/ (accessed 10 June 2021); Google, 'Monetisation and Ads - Payments' (Google Play Developer Policy Centre, 2019), available at https://support.google. com/googleplay/android-developer/answer/9858738 (accessed 10 June 2021). 
Probability disclosures do not restrict consumer choice, but only seek to better inform it. Similar disclosure requirements are imposed in regards to gambling in other jurisdictions 'to enable the customer to make an informed decision about his or her chances of winning. ${ }^{128}$ However, when discretion is given to gambling operators as to the amount; format and location of how such information is to be presented to consumers, gambling operators have arguably chosen suboptimal methods in order to misguide consumers. ${ }^{129}$ In the PRC, significant discretion is allowed to game companies as to where the probabilities should be disclosed: ${ }^{130}$ disclosures made either in-game on the loot box purchase page or the game's official website are both compliant with the law. ${ }^{131}$ However, arguably, a disclosure made ingame on the loot box's purchase page would appear more prominently to the consumer than a disclosure made on an official website, whose existence the player may not even be aware of. A disclosure made in-game would accordingly arguably be more likely to be read, and therefore be more effective at informing consumers and preventing overspending.

The PRC law also did not set out requirements as to how accessible the disclosures ought to be. For example, the disclosure in certain games can only be accessed if the player interacts with a tiny question mark hidden away in a corner of the loot box purchase screen; for other games, the disclosure can only be accessed after the player follows multiple hyperlinks on the official website. ${ }^{132}$ The disclosure could readily be provided more prominently and be more easily accessible, but many game companies have chosen not to provide this information in the most effective way. Indeed, the probability disclosure could be an automatic pop-up (with audio effects, such as an alarm sound) that interrupts purchase when the player attempts to buy loot boxes. Such an intrusive disclosure may be more effective at alerting the consumers as to the probabilities of obtaining rewards and preventing overspending. Apple, Google and the ESA have similarly not specified where the probabilities should be disclosed and how accessible the disclosure should be. The PRC law, and existing and prospective self-regulation, can be improved: specific requirements as to how, when and where probability disclosures should be made may ensure that disclosures are easy to access and understand, and are made at similar locations in all games, thus ensuring players playing multiple games and players playing a new game would readily be able to find the disclosures, and therefore be more effective at informing consumer choice and preventing overspending.

Disclosure rate of loot box probabilities has been assessed to be high in the PRC: $95.6 \%$ of the highestgrossing iPhone games containing loot boxes disclosed probabilities. ${ }^{133}$ However, the probabilities were not disclosed in the most prominent and accessible locations, and failed to communicate to consumers in the most effective ways. ${ }^{134}$ Further, a number of the disclosures made failed to provide sufficient detail as required by the PRC law, and some of the probabilities disclosed were evidently inaccurate (e.g., probabilities not summing to $100 \%) .{ }^{135}$ The compliance rate of the PRC legal obligation is therefore lower than the disclosure rate. The compliance rate of Apple's and Google's existing self-regulations, and the discretionary methods of compliance that game companies have chosen to adopt in relation to these self-regulations have not been assessed empirically in a comparative manner. This comparison between the PRC and another country, where only the self-regulations apply, would provide insight as to whether legal intervention was necessary or self-regulation alone is sufficient. Future research should examine these aspects to better inform future legal regulation and/or self-regulation.

A flaw with probability disclosures is that players cannot verify and thus be confident that the probabilities disclosed by the game companies are accurate. This is especially true in relation to voluntary disclosures and disclosures which are not scrutinized through some form of enforcement. Enforcement of the legal and self-regulatory requirements is necessary to ensure consumer confidence. The PRC law specified that proceeds generated through contraventions of the probability disclosure requirements would be confiscated and that the video game company would be fined between $¥ 10,000$ to $¥ 30,000$ Renminbi (approximately
128 See e.g., UK Gambling Commission, 'Remote Gambling and Software Technical Standards' (2017) 12, available at: https://web.archive.org/web/ 20210111083932/https://www.gamblingcommission.gov.uk/PDF/Remotegambling-and-software-technical-standards.pdf (accessed 10 June 2021).

129 Philip W.S. Newall, Lukasz Walasek and Elliot A. Ludvig, 'Equivalent Gambling Warning Labels Are Perceived Differently' (2020) 115 Addiction 1762 .

130 文化部 [Ministry of Culture] (PRC) (fn 123) para 6.

131 Xiao and others (fn 18). cf the more detailed guidance, which includes screenshots and examples, as to how to comply with probability disclosure

obligations provided by the South Korean self-regulation, see 한국게임산 업협회 [Korea Association of Game Industry; K-GAMES] (fn 124) 19-32. 132 For other methods of implementing probability disclosures adopted by various video game companies, see Xiao and others (fn 18).

133 Ibid.

134 Ibid.

135 Ibid. 
$£ 7,189$ to $£ 21,567) .{ }^{136}$ However, this penalty may no longer be effective because the Interim Administrative Measures for Online Games have since been abolished in July $2019 .{ }^{137}$ It is unclear how the PRC law is currently being enforced, if at all. ${ }^{138}$ Compliance with Apple's and Google's existing self-regulations appears to be based purely on trust in the self-declarations made by video game companies that they have complied with the platform providers' policies, ${ }^{139}$ and the probabilities disclosed by game companies are not scrutinized by either platform provider. In contrast, the South Korean self-regulation system, organized by K-GAMES (Korea Association of Game Industry), which provides a certification system that 'incentivizes' disclosure, has an enforcement system as set out in the Enforcement Rules of Self-regulation Code for Healthy Game Culture. ${ }^{140}$ Article 11 explains that the compliance of the most popular games on each platform will be monitored every month. ${ }^{141}$ Article 12 details that: for the first instance of identified non-compliance, the game company will be advised as to how it can comply; for the second offence, the company will be warned that it is non-compliant; and for the third offence, the company's violation will be identified and published to inform consumers and it will also be decertified. ${ }^{142}$ K-GAMES' monthly 'name and shame' admirably does not collude with influential game companies and does not discriminate against smaller game companies by only targeting them: Dota 2 (2013, Valve Corporation), one of the most popular MOBA games developed and published by Valve, a leading international video game company that developed and operates Steam, is prominently published at the top of the 'name and shame' list for repeated non-compliance. ${ }^{143}$

K-GAMES' self-regulatory system is exemplary: Apple's and Google's existing self-regulations, and the

136 See 文化部 [Ministry of Culture] (PRC) (fn 123) para 21, which refers to the penalties set out in 文化部 [Ministry of Culture] (PRC), '网络游戏管 理暂行办法(2017修订) [The Interim Administrative Measures for Online Games (2017 Amendment)] 文化部令第57号' (15 December 2017) para 31, available at: https://web.archive.org/web/20210305163127/http://www. pdsta.gov.cn/contents/12512/132633.html (accessed 10 June 2021).

137 文化和旅游部 [Ministry of Culture and Tourism] (PRC), “文化和旅游部 关于废止《网络游戏管理暂行办法》和《旅游发展规划管理办法》 的决定 [Decision on the Abolition of the Interim Administrative Measures for Online Games and the Measures for Planning and Administration of Tourism Development] 文化和旅游部令第2号' (10 July 2019), available at: http://www.gov.cn/zhengce/zhengceku/2019-12/02/con tent_5457656.htm (accessed 10 June 2021).

138 The Author reasons from anecdotal evidence (e.g., newspaper reports) that limited enforcement is carried out when competing game companies scrutinize and report each other, and when consumers report games that they are playing, to the PRC's official consumer protection hotline. See 任 [Ren] 震宇 [Zhenyu], “如何不让算法“算计”消费者 [How to prevent algorithms from manipulating consumers]' (中国消费者报 [China Consumer News], 15 January 2021), available at: https://web.archive.org/
ESA's prospective self-regulation should emulate K-GAMES' enforcement system by ensuring that the probability disclosures made by companies are accurate and can be trusted by consumers. However, it must be noted that even with a robust self-regulatory system, such as K-GAMES', some games remain non-compliant but continue to be popular with consumers. For example, Valve's Dota 2 has been declared non-compliant 19 times as of June 2020 by K-GAMES without inspiring any change to Dota 2's non-compliance and Valve's non-cooperation, ${ }^{144}$ which means that consumers remain at risk of potential harm. Indeed, self-regulation may not ultimately be effective as measures remain voluntary and may be ignored. Legal sanctions, such as fines (as originally provided for by the PRC law) and injunctions against the continued non-compliant operation of such games, may be the only reliable solution in such cases to guarantee compliance and consumer protection. A combination of the binding force of law and a robust enforcement regime may be a satisfactory step towards ameliorating the potential harms of loot boxes by responsibly informing consumers of the (un)likelihood of obtaining specific rare rewards and the potential harms of paid loot boxes.

\subsection{Maximum spending limits}

As identified above, the most concerning issue with loot boxes is overspending. ${ }^{145}$ More ethically designed implementations of loot boxes are defensible and need not necessarily be prohibited. The probability disclosure measure discussed above may assist players in making more informed decisions and therefore becoming less likely to overspend. However, it is possible to be more interventionist by literally preventing overspending by setting a maximum limit on the amount of

web/20210217235907/http://zxb.ccn.com.cn/shtml/zgxfzb/20210115/ 164737.shtml (accessed 10 June 2021).

139 Apple (fn 127).

140 See 한국게임산업협회 [Korea Association of Game Industry; K-GAMES] (fn 124) 40-43.

141 Ibid 42

142 Ibid.

143 한국게임산업협회 [Korea Association of Game Industry; K-GAMES], ‘확률형아이템 자율규제 미준수 게임물 19차 공표 [The 19th Announcement of Games Which Are Non-Compliant with Self-Regulatory Probabilities Disclosure Obligations]' (22 June 2020) 2, available at: http://www.gsok.or.kr/wp-content/uploads/2020/06/\%EB\%B3\%B4\%EB\% 8F\%84\%EC\%9E\%90\%EB\%A3\%8C\%ED\%99\%95\%EB\%A5\%A0\%ED\%98\% 95\%EC $\% 95 \% 84 \% \mathrm{EC} \% 9 \mathrm{D} \% \mathrm{~B} 4 \% \mathrm{ED} \% 85 \% 9 \mathrm{C}-\% \mathrm{EC} \% 9 \mathrm{E} \% 90 \% \mathrm{EC} \% 9 \mathrm{C} \%$ A8\%ЕA\%B7\%9C\%EC\%A0\%9C-\%EB\%AF\%B8\%EC\%A4\%80\%EC\%88\% 98-\%ЕA\%B2\%8C\%EC\%9E\%84\%EB\%AC\%BC-19\%ЕC\%B0\%A8-\%ЕA\% B3\%B5\%ED\%91\%9C.pdf (accessed 10 June 2021).

144 Ibid.

145 See text to fns 92-93. 
money players are allowed to spend on loot boxes. In gambling contexts, 'pre-commitment limit-setting involves users specifying (voluntarily or compulsorily), before engaging in gambling, the maximum they would like to spend. Once reached, this limit triggers a reminder message and a cooling-off period in which the player is unable to gamble further'. ${ }^{146}$ Pre-commitment limit-setting is known to have a positive, if subtle, effect on reducing and controlling problem gambling: ${ }^{147}$ although it may not necessarily be the monetary limit itself that curtails the gambling behaviour, but rather the 'break in play', i.e., that the gambler is forced to stop playing, cool off, step back and think rationally, which is effective. ${ }^{148}$

The most difficult issue with setting a maximum spending limit is deciding how much this limit should be, as regulators would need to make an assessment as to what is a fair and equitable amount of money to be spent on a game for a specific period of time, and arguably arbitrarily impose this on all players regardless of their individual, personal circumstances. ${ }^{149}$ Drummond, Sauer and Hall recommended a monthly cap

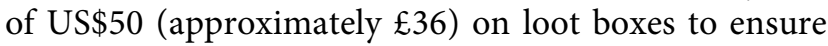
the protection of players who would be classified as problem gamblers (i.e., those who would significantly overspend on loot boxes). ${ }^{150}$ US $\$ 50$ is not necessarily the most optimal amount of money to spend on loot boxes for every individual consumer: indeed, US $\$ 50$ may be quite a lot more money than many players, especially children, would be willing or allowed to spend on a game per month, but US\$50 may also be much less than what an affluent player may want to spend monthly to financially support their favourite game developer. However, a monthly limit of US $\$ 50$ may be appropriate because it is close to how much a player would be expected to pay when purchasing a video game outright 'as a product'151 (it is quite

146 Aaron Drummond, James D. Sauer and Lauren C. Hall, 'Loot Box LimitSetting: A Potential Policy to Protect Video Game Users with Gambling Problems?' (2019) 114 Addiction 935, 935; cf King and Delfabbro, 'Loot Box Limit-Setting Is Not Sufficient on Its Own to Prevent Players from Overspending' (fn 41).

147 Andrew Harris and Mark D. Griffiths, 'A Critical Review of the HarmMinimisation Tools Available for Electronic Gambling' (2017) 33 Journal of Gambling Studies 187, 214-215.

148 Ibid 213.

$149 \mathrm{cf}$ the PRC judiciary recently expressed perfect willingness to engage with this assessment in relation to how much money a particular child should be allowed to spend on video games given their family's economic circumstance and the game's 'genre' on a case-by-case basis: their jurisprudence on this point may be insightful once generated, see Leon Y. Xiao, 'People's Republic of China Legal Update: Supreme People's Court's Guiding Opinion on Refund Requests Relating to Unauthorised Online Video Gaming Transactions Paid for by Minors (Published 15 May 2020)' (2020) 24 Gaming Law Review 476.

150 Drummond, Sauer and Hall (fn 146) 935. reasonable for such a game to be purchased, and for such an amount of money to be spent on video gaming, every month); and because monetizing with loot boxes, in a non-predatory manner, and selling game titles outright are equally valid monetization methods that game companies may adopt and therefore should be treated equally by the law. A relevant point to consider is that the law may be able to disincentivize the implementation of loot boxes by decreasing the maximum monthly spending limit on loot boxes to be lower than the average price of a game software to discourage game companies from monetizing with loot boxes, as they would be forced to only be able to generate less revenue per player if they choose to monetize with loot boxes, rather than otherwise.

Monthly maximum spending limits on online video games generally (but not limits on loot box spending specifically) have been imposed in South Korea and the PRC against players. These laws provide comparative insights. The South Korean monthly limits were previously imposed on 'juveniles' under the age of 19 at \#70,000 South Korean Won (approximately $£ 44$ ) and on adults at $\$ 500,000$ South Korean Won (approxi-

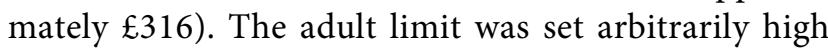
and would only have been capable of preventing particularly extreme overspending. Notably, both South Korean limits 'have since been repealed citing unfair economic discrimination against the video game industry as compared to other creative industries'. ${ }^{152}$ The PRC had imposed an impractical and unreasonable monthly limit of $¥ 10$ Renminbi (approximately $£ 1.10$ ) on minors under the age of 18 in March 2011. ${ }^{153}$ This limit has been updated in November 2019: minors under the age of 8 are prohibited from spending any money at all; minors aged between 8 and 16 are allowed to spend up to $¥ 200$ Renminbi (approximately $\mathfrak{E 2 2}$ ); and minors aged between 16 and 18 are allowed to spend

151 The average unit price of a video game software in the UK in 2017 was $£ 33.47$, see Katrin Kienast, 'Video Game Software: Unit Price in the UK 2008-2017' (Statista, 25 June 2018), available at: https://www.statista. com/statistics/282012/video-game-software-unit-price-in-the-unitedkingdom-uk/ (accessed 10 June 2021)

152 Leon Y. Xiao, 'People's Republic of China Legal Update: The Notice on the Prevention of Online Gaming Addiction in Juveniles (Published October 25, 2019, Effective November 1, 2019)' (2020) 24 Gaming Law Review 51, 53; see 문화체육관광부 [Ministry of Culture, Sports and Tourism (South Korea)], '보도자료 - 피시(PC)•온라인게임 성인 결제한도 폐지 [Press Release - Repeal of Maximum Spending Limit for PC and Online Games Imposed on Adults]' (2019), available at: https://www.mcst.go.kr/kor/ s_notice/press/pressView.jsp?pSeq=17352 (accessed 10 June 2021).

153 文化部 [Ministry of Culture] (PRC) and others, “关于印发《“网络游戏 未成年人家长监护工程”实施方案》的通知 [Notice on the Publication of the "Parental Monitoring of the Online Gaming of Minors Project' Implementation Plan”] 文市发[2011]6号” (15 January 2011) app 2, art 2, available at: http://old.moe.gov.cn//publicfiles/business/htmlfiles/moe/ moe_1779/201105/119727.html (accessed 10 June 2021). 
$¥ 400$ Renminbi (approximately $£ 44$ ). ${ }^{154}$ These updated limits are more realistic; however, their regulatory effects remain to be assessed.

Enforcement of maximum spending limits on video games may prove difficult. In the gambling context, pre-commitment maximum spending limits have proven difficult to impose compulsorily: gamblers may be able to switch to another service provider to evade the limit and gamble more (although this issue may be avoided if providers share information between each other). ${ }^{155}$ Such enforcement difficulties are similarly present in the video gaming context. Both South Korea and the PRC are countries that have universal national identification card systems that advantageously allow for the verification of the real-life identity of all online players (i.e., all user accounts must belong to a verified reallife identity), which then allows for age verification and, potentially, the enforcement of maximum spending limits against those players across multiple user accounts; games; video gaming service providers; and hardware platforms. However, identity verification regulations have been documented to have been easily bypassed by minors in both South Korea and in the PRC through using the personal identification documents of others, such as the minor's parents' or the internet café operators'. ${ }^{156}$

In countries without universal identification systems, e.g., the $\mathrm{UK},{ }^{157}$ these limits are even more difficult to impose against individuals. ${ }^{158}$ The alternative imposition of these limits against only the player's user account, rather than the player's real-life identity, can be circumvented through the creation and use of multiple accounts for the same game, or by simply switching to playing another game. However, unlike in gambling contexts where the gambling game's game design cannot realistically be changed, the multiple account issue can be resolved through ethical game design by heavily disincentivizing the player for possessing multiple accounts, e.g., progression through the game requires virtual items that cannot be directly bought using real-world money or transferred between accounts, and must be earned through gameplay, thus effectively forcing players to only be able to invest time in and play on one account. Admittedly, this requires the unlikely voluntary

154 Xiao, 'The Notice on the Prevention of Online Gaming Addiction in Juveniles' (fn 152) 52; 国家新闻出版署 [National Press and Publication Administration (PRC)], ‘关于防止未成年人沉迷网络游戏的通知 [Notice on the Prevention of Online Gaming Addiction in Juveniles]' (25 October 2019) art 3, available at: http://www.sapprft.gov.cn/sapprft/ contents/6588/407807.shtml (accessed 10 June 2021).

155 Harris and Griffiths (fn 147) 214

156 Jiyun Choi and others, 'Effect of the Online Game Shutdown Policy on Internet Use, Internet Addiction, and Sleeping Hours in Korean Adolescents' (2018) 62 Journal of Adolescent Health 548, 549, 551-552; Jing commitment to this measure from the entire video game industry (because such game design would be commercially detrimental: such virtual items linked to progression would sell well), as otherwise the player would simply choose to switch to games with more unscrupulous operators.

What would be an ideal maximum spending limit on loot boxes, if it is to be imposed? In the Author's view, a universal monthly US\$50 limit may be too low. Considering individual circumstances, a particular player spending US\$100 (approximately $£ 72$ ) monthly on the only game that they play every day for many hours may not be unreasonable and should not be restricted. A higher monthly limit of US\$200 (approximately $£ 144$ ) per game should be set universally as law to prevent extreme overspending on one particular video game. Game companies are welcome to set a lower limit for their games if they deem it more ethical to do so (for example, a game company may voluntarily set a lower monthly US\$30 (approximately $£ 22$ ) limit for their child players). This overarching legal limit could then be complemented: individual players' past spending behaviour would be examined in a socially responsible and benevolent manner (rather than malevolently and abusively to derive additional commercial gain ${ }^{159}$ ) to identify potential problematic spenders, then such users are advised as to the potential harms of overspending on loot boxes; provided with resources to participate in support programmes; and, importantly, offered the option to set lower limits on their own future spending on loot boxes. Ideally, the spending limits of various video games would be organized into one centralized management system using which the player may be able to not only set individual spending limits on a particular game, but also a total spending limit on all games.

In terms of self-regulation, game companies do not necessarily need to implement their own maximum spending limit against user accounts as a hard cap on spending: instead, the loot box mechanic can be designed to be 'exhaustible', such that once a predetermined amount of money is spent (i.e., the intended maximum spending limit is reached), all rewards are guaranteed to be given to (or 'won' by) the player. It is also important to ensure that rewards do not expire or

Da Zhan and Hock Chuan Chan, 'Government Regulation of Online Game Addiction' (2012) 30 Communications of the Association for Information Systems 193, available at: https://aisel.aisnet.org/cais/vol30/iss1/13 (accessed 10 June 2021).

157 See Identity Documents Act 2010 s 1 repealing the Identity Cards Act 2006

158 Xiao, 'The Notice on the Prevention of Online Gaming Addiction in Juveniles' (fn 152) 52, fn 2.

159 King and others (fn 49). 
cannot be expended, such that players need not make repeat purchases to obtain the same rewards. ${ }^{160}$ Game companies can also additionally provide an alternative (reasonably priced) option for the player to buy all possible rewards (or even specific rewards) from the loot box mechanic in a non-randomized manner for a predetermined amount of money. Combined with an exhaustible loot box design, this provides players with the choice to either engage with the loot box mechanic for a potential chance to win the most desirable rewards at a discount, or to directly purchase all desired items upfront.

\subsection{Maximum gameplay time limits and curfew laws}

In addition to maximum spending limits, video gaming has also been regulated and restricted using the concept of time, rather than money. Such measures may not be directly applicable to loot box spending, but may provide certain insights from a regulatory perspective. Maximum gameplay time limits seek to limit the total amount of time that a player is allowed to play games. Curfew shutdown laws restrict players from playing games during certain times, e.g., late nights and early mornings to ensure adequate sleep time, or school hours to ensure attendance. Both measures are aimed towards reducing gameplay time rather than in-game spending; nonetheless, the implications of their imposition are insightful. Recently imposed rules in the PRC limit minors' gameplay time to 3 hours on public holidays, including weekends, and 1.5 hours on other (regular) weekdays. ${ }^{161}$ In April 2020, the Kagawa Prefecture of Japan imposed regulations on minors under 20 years old by limiting their gameplay time to 'no more than 60 minutes on school nights and an hour and a half on weekends'. ${ }^{162}$ The PRC further restricts minors under the age of 18 from online gaming services between 22:00 and 8:00. ${ }^{163}$ Similar curfew laws on online games have been imposed 'between 0:00 and 6:00 in South Korea on juveniles under the age of 16 by Article 26(1) of the Juvenile Protection Act' since 2011. ${ }^{164}$

Such measures are particularly paternalistic as they severely restrict the liberty of the individual, which is likely why they have thus far only been imposed against minors. This suggests that loot box regulation may potentially also need to be applied differently against child and adult players, and against children of different ages. Temporal restriction measures have been documented to cause economic harm against the game industry, and have been argued to even potentially infringe fundamental human rights, 'such as the underage players' right to pursue happiness and self-determination, their parents' right to educate their children and the game companies' freedom of expression' ${ }^{165}$ Indeed, the regulations imposed by the Kagawa Prefecture of Japan are presently under a constitutional challenge on the grounds that they 'violate the constitutional rights to freedom of expression and limits on the government's authority'. ${ }^{166}$ Stringent loot box (over)regulation may cause similar harms.

Measures restricting gameplay time have also proven difficult to enforce because they are easily circumvented using the personal identification documents of others. ${ }^{167}$ Notably, psychology research has concluded that the South Korean curfew law has been ineffective from a regulatory perspective because it neither reduced adolescent internet usage nor increased adolescent sleeping hours, as were its legislative intent. ${ }^{168}$ This is meaningful for loot box regulation and suggests that more interventionist regulatory 'solutions' (such as banning all paid loot boxes) may not be appropriate without empirical research evidence. Such overregulation fails to protect consumers and harms the industry economically, and therefore should be avoided. The call for video game companies to be socially responsible by releasing loot box purchase data and cooperating with independent researchers, in order to avoid imminent, harmful overregulation, is worth repeating.

\subsection{Disabling cash-out features}

'Cash-out' features refer to methods by which in-game items can be transferred between players and thus gain real-world value (e.g., inter-player trading and auction houses). In-game item transfer systems in multiplayer games being misused for money laundering has been
160 King and Delfabbro, 'Video Game Monetization (e.g., "Loot Boxes”)' (fn 93) 171.

161 国家新闻出版署 [National Press and Publication Administration (PRC)] (fn 154) art 2.

162 Ben Dooley and Hikari Hida, 'A Government in Japan Limited Video Game Time. This Boy Is Fighting Back' (The New York Times, 11 June 2020), available at: https://www.nytimes.com/2020/06/11/business/japanvideo-games.html (accessed 10 June 2021).

163 国家新闻出版署 [National Press and Publication Administration (PRC)] (fn 154) art 2.
164 Xiao, 'The Notice on the Prevention of Online Gaming Addiction in Juveniles' (fn 152) 52.

165 Xiao and Henderson (fn 54) 10-11; citing Byung-gwan Kim, 'Implications of Forced Shutdown in the Fourth Industrial Revolution' (2018) 33 KISO Journal, available at: https://journal.kiso.or.kr/?p=9248 (accessed 10 June 2021).

166 Dooley and Hida (fn 162).

167 Choi and others (fn 156) 551-552.

168 Ibid 551. 
well-documented by the media in the PRC. ${ }^{169}$ In October 2019, the ability to cash-out was disabled globally for Counter-Strike: Global Offensive (CS:GO) (2012, Hidden Path Entertainment \& Valve Corporation) by the Game's publisher because 'worldwide fraud networks have recently shifted to using CS:GO keys to liquidate their gains, [such that] nearly all key purchases that end up being traded or sold on the marketplace are believed to be fraud-sourced'. ${ }^{170}$ This may have been done in recognition of potential intermediary liability, as these video game features are facilitating criminality. Additionally, issues with the validity and legality of the transfer of ownership (potentially involving minors with no legal capacity) over decentralized virtual items and currency, whose value may be particularly volatile and subject to little, if any, regulatory oversight, also arise. ${ }^{171}$

Game companies have complied with the Dutch gambling regulator's requirement to disable cash-out features, albeit sometimes unwillingly and with much protestation. ${ }^{172}$ The UK and French regulators have also recognized the possible abuse of cash-out features, but have yet to act against demonstrable current cases (arguably a failure of their executive function). ${ }^{173}$ Considering existing evidence of criminal abuse, there is a substantial public policy reason to subject cash-out features to additional regulatory scrutiny. Existing self-regulatory measures that discourage abusing in-game item transfer systems to cash-out, such as by telling players not to do so and punishing players caught doing so by banning or restricting their user accounts, ${ }^{174}$ are insufficient, because abuse remains factually possible as these measures respond only after the abuses have occurred and after harm has already been caused. Some players would always be willing to risk account termination to cash-out, particularly when they are quitting the game. Only the blanket ban of cash-out features can completely prevent abuse. Until cash-out features can be technologically secured such that they could not be abused, they should not be implemented in new games and should be disabled in existing games.

169 See e.g. 新浪游戏 [Sina Games], “网络游戏缘何变“洗钱”平台 [How Online Games Became Platforms for Money-Laundering]' (5 September 2013), available at: http://games.sina.com.cn/y/n/2013-09-05/ 1116731339.shtml (accessed 10 June 2021); 腾讯游戏 [Tencent Games]; “团伙网上诈骗百万元 通过游戏账户充值洗钱 [Criminal Gang Committed Million-Yuan Online Fraud and Money-Laundering by Purchasing Microtransactions with Video Game Accounts]' (26 October 2014), available at: https://games.qq.com/a/20141026/016665.htm (accessed 10 June 2021).

170 Valve Corporation, 'Key Change' (28 October 2019), available at: https:// blog.counter-strike.net/index.php/2019/10/26113/ (accessed 10 June 2021) emphasis added.

171 See Xiao, 'Supreme People's Court's Guiding Opinion on Refund Requests' (fn 149).
This is the position that the Dutch regulator has enforced. ${ }^{175}$ Therefore, game companies can be reasonably expected to understand how to comply with this regulatory position. The UK and French regulators are also theoretically aligned with this position, although they have not enforced it. Video game companies are in a better position than gambling regulators to understand when and how in-game item and virtual currency transfer systems they have implemented may be abused by players. Gambling regulators may not necessarily be able to identify each case easily and promptly. Certain currently non-compliant game companies should act now to disable cash-out features; voluntarily comply with UK and French law; and prevent potential harms to consumers, instead of waiting until the regulators decide to finally enforce the law against them. Similarly, if game companies are willing to comply with Dutch law to better protect consumers in the Netherlands, then they should also socially responsibly apply the same higher standard of consumer protection to all their consumers in every jurisdiction, rather than merely complying minimally with the law (or, in the case of UK and French law, be knowingly non-compliant with the law until it is enforced against them).

\subsection{Ethical game design 'tool box': consumer protection measures applied simultaneously}

Recognizing the practical difficulties with regulating using and enforcing ethical game design measures detailed above, ${ }^{176}$ these measures are nonetheless likely to be effective at reducing overspending on loot boxes to an extent and should still be imposed where possible. Pre-commitment limit-setting in gambling contexts only reduces gambling to a limited extent, ${ }^{177}$ and maximum spending limits in video games would be difficult to effectively impose compulsorily by regulators in all countries. Therefore, the imposition of any one measure (such as setting maximum spending limits) cannot be perceived as a singular, permanent solution to loot box

172 For example, 'While we disagree with this position, we are working to comply with Kansspelautoriteit's current interpretation of these laws.' See 2K Games, 'Statement Netherlands' (fn 115).

173 Xiao, 'Which Implementations of Loot Boxes Constitute Gambling?' (fn 1). See text to fns 109-111.

174 See e.g., Electronic Arts (EA), 'Be Safe with FUT Coins and FIFA Points' (4 September 2019), available at: https://help.ea.com/en/help/fifa/be-safewith-fut-coins-and-fifa-points/ (accessed 10 June 2021); Electronic Arts (EA), 'Know the Rules in EA SPORTS FIFA' (20 September 2019), available at: https://help.ea.com/en/help/fifa/fifa-rules/ (accessed 10 June 2021).

175 See text to fns 106-108.

176 See Xiao and Henderson (fn 54).

177 Harris and Griffiths (fn 147). 
harms. ${ }^{178}$ Multiple measures should be imposed simultaneously. The ineffectiveness of the curfew law in South Korea at reducing internet usage or increasing sleeping hours, and its economic harms, demonstrate that the regulation of technology, particularly video gaming, requires a process of trial and error. The regulation of technology is difficult and its impact unpredictable. Therefore, regulators should experiment with multiple measures simultaneously with the aim of measuring their effects, after being sufficiently informed by empirical research. Additional ethical game design measures to consider include, amongst others: not offering limitedtime-only loot boxes containing unique rewards, so as to not induce an unfair sense of artificial urgency in the player; ${ }^{179}$ not adopting the pay-to-win model ${ }^{180}$ by not offering loot box rewards that provide a competitive advantage; ${ }^{181}$ and ensuring that loot box rewards can also realistically be obtained either through gameplay without payment or through direct (rather than randomized) purchase. ${ }^{182}$

For ethical game design to succeed, players and game companies must be accepting of the concept. Xiao and Henderson argued that players may be averse to these measures and perceive them as paternalistic. ${ }^{183}$ However, on the contrary, it is especially encouraging that a survey of Norwegian gamblers has demonstrated that $80 \%$ of them have a positive attitude towards maximum spending limits, even though it was compulsorily imposed, and that very few actually sought alternative operators after they reached their limit. ${ }^{184}$ Therefore, players can be reasonably expected to support these ethical game design measures once they appreciate that these measures are implemented for their protection.

Admittedly, there are practical difficulties with convincing video game companies to voluntarily adopt these measures as many of them are plainly not commercially beneficial as their adoption will negatively impact revenue. ${ }^{185} \mathrm{~A}$ few established game companies have voluntarily implemented some of these principles to a certain degree: ${ }^{186}$ for example, Path of Exile (2013,

178 King and Delfabbro, 'Loot Box Limit-Setting Is Not Sufficient on Its Own to Prevent Players from Overspending' (fn 41).

179 King and Delfabbro, 'Video Game Monetization (e.g., "Loot Boxes")' (fn 93) 172.

180 See fn 81 . This also leads to 'power-creep' which arguably destroys consumer confidence in the product and is unsustainable from a game design perspective as more and more powerful items need to be created, see Mark Rosewater, 'Why Is Power Creep a Bad Thing?' (Blogatog, 31 January 2016), available at: https://markrosewater.tumblr.com/post/ 138448198918/why-is-power-creep-a-bad-thing (accessed 10 June 2021); Sam Stoddard, 'Dealing with Power Creep' (Magic: The Gathering Official Website, 9 August 2013), available at: https://magic.wizards.com/en/arti cles/archive/latest-developments/dealing-power-creep-2013-08-09 (accessed 10 June 2021).
Grinding Gear Games) and Overwatch only sell loot boxes containing cosmetic items which do not confer competitive advantages, and Hearthstone allows the possibility for players to obtain all loot box rewards through gameplay and provides uses for duplicate rewards to ensure that they would still be somewhat useful. ${ }^{187}$ There may be certain, albeit limited, potential PR (public relations) benefits to adopting ethical game design, i.e., the media and the public choosing to give recognition and custom to certain game companies for their demonstrated social responsibility. For example, video gaming media widely reported on Fortnite's implementation of $\mathrm{X}$-Ray Llamas and Epic Game's commitment to 'loot box transparency'. ${ }^{188}$ Indeed, public and commercial pressures can encourage ethical game design practices from the industry and ensure their adoption: consumers should exert pressure by voting with their wallets and choosing to spend their money only on ethically designed video games, and governments should, through discretionary grants and tax relief, incentivize the cessation of the implementation of potentially abusive game mechanics and the adoption of ethical game design principles. ${ }^{189}$

The adoption of ethical game design also has the long-term benefit of ensuring that game companies would not seek to invent other potentially abusive mechanics to replace loot boxes after loot boxes become regulated, and thereby force academics and regulators to again scramble to identify the potential harms of another newly invented monetization method and justify their regulation, whilst exposing consumers to potential harms in the meantime before regulation is finally again made. Some concerns have already been raised against the relatively newer 'season pass' mechanic, which allows players to spend money to gain access to the opportunity to collect points during a specific, limited period of time and receive substantial rewards: it has been suggested that video game companies have not all been transparent to players as to how much gameplay time, and how much more money (in addition

181 King and Delfabbro, 'Video Game Monetization (e.g., "Loot Boxes")' (fn 93) 171.

182 Ibid $170-171$

183 Xiao and Henderson (fn 54) 6-7.

184 Michael Auer, Sigrun Høvik Reiestad and Mark D Griffiths, 'Global Limit Setting as a Responsible Gambling Tool: What Do Players Think?' (2020) 18 International Journal of Mental Health and Addiction 14.

185 Xiao and Henderson (fn 54) 5-6.

186 Matthew McCaffrey, 'The Macro Problem of Microtransactions: The SelfRegulatory Challenges of Video Game Loot Boxes' (2019) 62 Business Horizons 483, 489-481.

187 Xiao and Henderson (fn 54) 2.

188 See text to $\mathrm{n} 77$.

189 Xiao and Henderson (fn 54) 12-13. 
to the initial purchase of the season pass, because players can pay to buy points directly), are still required to be spent, before enough points can be collected to receive all of the season pass's rewards. ${ }^{190}$

\subsection{Past instances of minimal compliance by game companies sowed distrust}

Voluntary self-regulation is likely the best solution, if all elements of the video game industry can be trusted to comply and endeavour to ensure consumer protection to the best of their abilities. Unfortunately, self-regulation alone as a solution must be treated with scepticism because major game companies have often only acted when explicitly regulated against and have not sought to promote consumer protection to the fullest and uniformly across jurisdictions. ${ }^{191}$ Consumers in Belgium are now protected from the potential harms of all paid loot boxes only because of the regulatory action of the Belgian gambling regulator; ${ }^{192}$ consumers in the Netherlands are protected from cash-out features, but not from overspending on paid loot boxes that do not contain rewards that are worth real-world money, because of the comparatively more limited regulatory action of the Dutch gambling regulator; ${ }^{193}$ and consumers in the UK and France and most other countries remain largely unprotected from cash-out features and overspending, because of a lack of substantive regulatory action (e.g., enforcement). The disclosure of the probabilities of obtaining rewards from loot boxes was initially published by major game companies only because of the imposition of PRC law and only in Simplified Chinese for the benefits of PRC players. ${ }^{194}$ Although the disclosures were often immediately translated into English and published online by dedicated Chinese players for the benefits of international players, technically and officially, many of the disclosures have not yet been made available to players from non-PRC countries. Game companies have not endeavoured to provide this

190 Elena Petrovskaya and David Zendle, 'The Battle Pass: A Mixed-Methods Investigation into a Growing Type of Video Game Monetisation' 8, 11, available at: https://osf.io/vnmeq/ (accessed 10 June 2021).

191 Xiao and Henderson (fn 54) 8-9; Hong (fn 117) 79; cf the perspective from the industry, see Kerry Hopkins, Oral Evidence (Question 1150) to the Immersive and Addictive Technologies Inquiry of the Digital, Culture, Media and Sport Committee of the House of Commons (UK) (2019), available at: http://data.parliament.uk/writtenevidence/committeeevi dence.svc/evidencedocument/digital-culture-media-and-sport-committee/ immersive-and-addictive-technologies/oral/103191.pdf (accessed 10 June 2021).

192 See e.g., Blizzard Entertainment, 'Paid Loot Boxes and Loot Chests Disabled for Players in Belgium' (Official Overwatch Forums, 27 August 2018), available at: https://eu.forums.blizzard.com/en/overwatch/t/paidloot-boxes-and-loot-chests-disabled-for-players-in-belgium/8139 (accessed 10 June 2021); 2K Games, 'Statement Belgium' (fn 115); Nintendo (fn 89). information as soon as possible to all players in manners most accessible to them, and instead they have only complied minimally by providing this information only to PRC players. Video game companies have not acted socially responsibly in relation to the potential harms of loot boxes over the past few years, and this casts significant doubt on whether the industry can be trusted to self-regulate effectively without legal intervention. The Author believes not.

\section{Conclusion: a combined legal and self-regulatory approach to loot boxes}

The level of consumer protection provided by game companies often depends on the legal regulation in place, which is why it is necessary for legal regulation to set a minimum acceptable standard to ensure a sufficient degree of consumer protection, in the absence of proactive voluntary self-regulation. The best solution going forward with loot box regulation may be for the law to set a minimum standard that does not overregulate, and for self-regulation to complement the legal regime by striving to achieve an even higher standard of consumer protection.

In terms of the two types of paid loot boxes, this combined approach would require that the law either prohibit, or regulate as licensed gambling, loot boxes whose rewards are worth real-world money, depending on whether gambling is either prohibited or regulated in the jurisdiction, so as to potentially allow video gaming companies to expand into the regulated, licensed gambling industry in certain jurisdictions. The combined regulatory approach would ensure that loot boxes whose rewards are worth real-world money cannot be sold to children (which addresses an issue of particular concern to academics; regulators; policymakers; the media; and the public), and that their sale to adults

193 See e.g., 2K Games, 'Statement Netherlands' (fn 115).

194 For example, 'In response to the Ministry of Culture's new regulations ...' See DOTA2运营团队 [Chinese Dota 2 Operations Team], “应文化部新 政策要求关于珍藏概率与结果的公示 [Disclosures in Response to New Regulations Issued by the Ministry of Culture Concerning the Drop Rates and Results of Loot Boxes]' (Chinese Dota 2 Website, 2 May 2017), available at: https://www.dota2.com.cn/article/details/20170502/ 194771.html (accessed 10 June 2021); See also Blizzard Entertainment, “关于《守望先锋》补给抽取概率公告 [Notice on the Drop Rates of Overwatch Loot Boxes]' (Official Chinese Overwatch Website, 23 March 2017), available at: https://ow.blizzard.cn/article/news/486 (accessed 10 June 2021); Blizzard Entertainment, “关于《炉石传说》卡牌包抽取概 率的公示方式调整公告 [Notice on the Amended Drop Rates of Hearthstone Packs]' (Official Chinese Hearthstone Website, 2 August 2018), available at: http://hs.blizzard.cn/touch/articles/20/9546 (accessed 10 June 2021). 
will be strictly scrutinized (and taxed) as gambling by regulators. Cash-out features should be restricted by law (which should be strictly enforced) at present until they can be technologically secured, at which point the law may be disapplied and cash-out features will be self-regulated as game companies would be in a better position to identify and prevent abuse.

The other type of paid loot boxes, those whose rewards are not worth real-world money, need not necessarily be prohibited or regulated as gambling (and in fact, in the Author's view, should not be, because they can be conceptually differentiated). To prevent overspending, a reasonable but considerably high maximum spending limit (which may be set at different values for adults and children, and for children of various ages, and thus should resolve academics'; regulators'; policymakers'; the media's; and the public's particular concern as to children overspending on loot boxes) should be imposed as law, and game companies should be encouraged to complement this legal requirement by restricting player spending further by imposing lower spending limits, or by ensuring that all loot box rewards are guaranteed to be obtained for a predetermined and reasonable amount of money.

To facilitate the adoption of ethical game design, where possible, the law should impose certain ethical game design measures as law: for example, the obligation to disclose the probabilities of obtaining randomized rewards. The law should detail a specific and uniform way for communicating such information to players, that is sufficiently prominent, accessible and easy to understand, and the law should contain an enforcement regime that is capable of punishing non-compliant game companies. Game companies should be encouraged to improve on this legal requirement by providing additional, even more prominent and easy-to-understand ways for players to access probability disclosures. Other ethical game design measures which cannot realistically be codified (because they would require the arguably impossible exercise of subjective discretion by a yet-to-be-established video gaming regulatory body ${ }^{195}$ ) should be promoted to game companies through incentives, such as a certification regime, discretionary grants and tax relief. Instead of having a prospective regulator decide what is ethical game design per se and prohibit 'abusive game design', the video game industry should lead this effort as its members are in the best position to evaluate the 'ethics' of game design. Finally, consumers should be informed of the benefits of ethical game design and encouraged to support only ethically designed video games.

\section{Acknowledgements}

The Author would like to thank Miss Laura L. Henderson, Dr Zhiyu Li, Dr Daniel Seng, Dr Alex Mitchell and Dr Niklas Ihssen. The views expressed herein are solely the Author's. All errors and omissions remain his own. This article draws on the Author's LLB dissertation completed at Durham Law School, Durham University in March 2020. A $2018 \mathrm{draft}$ of this article was entitled 'Online Gambling in Video Games: A Case Study on the Regulation of Loot Boxes'. A 2019 draft was entitled 'A Primer on the Legal Regulation of Loot Boxes: History, Business, Psychology, Law and Regulation'. A 2020 draft was entitled 'Regulating Loot Boxes as Gambling? Perspectives from Psychology, Behavioural Economics and Ludology'. This article was presented at the 111th Society of Legal Scholars Annual Conference 2020. The Author is grateful for the helpful comments received. The manuscript was received on 19 November 2019, revised on 4 August 2020, and accepted on 1 March 2021. Currency conversions were calculated using the currency exchange rates on 12 March 2021. This article is not intended to constitute or be relied upon as legal advice. The law is stated as at 12 March 2021. 